DIW BERLIN

Discussion Papers
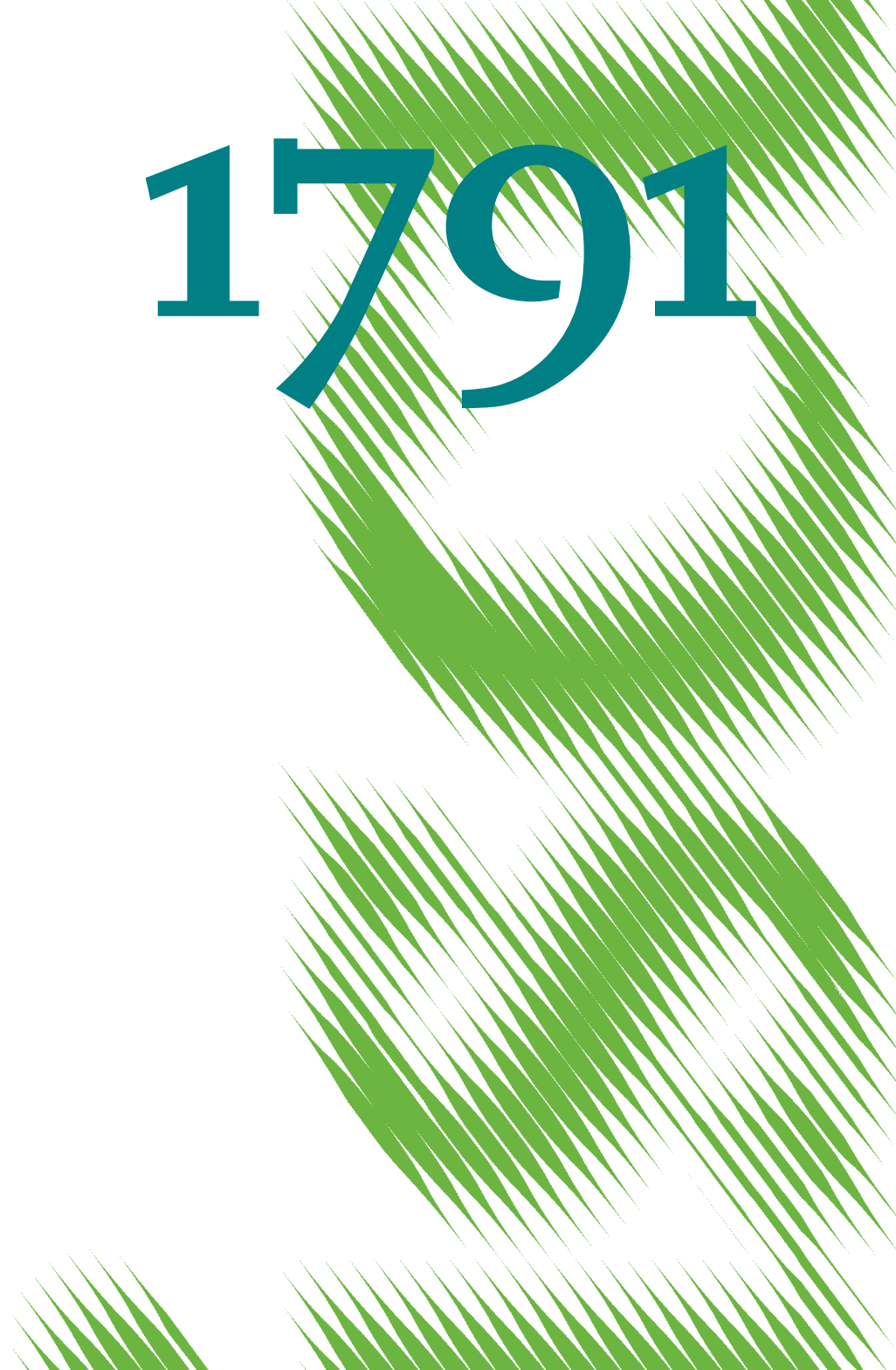

MIMMMMMMMMT

The Part-Time Wage Gap across the Wage Distribution 
Opinions expressed in this paper are those of the author(s) and do not necessarily reflect views of the institute.

IMPRESSUM

(C) DIW Berlin, 2019

DIW Berlin

German Institute for Economic Research

Mohrenstr. 58

10117 Berlin

Tel. +49 (30) $89789-0$

Fax +49 (30) $89789-200$

http://www.diw.de

ISSN electronic edition 1619-4535

Papers can be downloaded free of charge from the DIW Berlin website:

http://www.diw.de/discussionpapers

Discussion Papers of DIW Berlin are indexed in RePEc and SSRN:

http://ideas.repec.org/s/diw/diwwpp.html

http://www.ssrn.com/link/DIW-Berlin-German-Inst-Econ-Res.html 


\title{
The Part-Time Wage Gap across the Wage Distribution
}

\author{
Patricia Gallego Granados*
}

February 2019

\begin{abstract}
Part-time work has vastly expanded in most OECD labor markets during the last decades. At the same time, full- and part-time wages have grown increasingly apart, leading to a substantial raw part-time wage penalty. Using quantile regression methods, this paper analyses the female part-time wage gap across the wage distribution and over time (1990-2009), while controlling for sample selection into full- and part-time employment. The estimated part-time gap is much lower than the raw gap. Nonetheless, a persistent part-time penalty is found for the lowest wage quartile. The wide divide between the observed and estimated part-time gap is due to strong positive selection into full-time work, which increases over time. On the contrary, sample selection into part-time employment goes from being positive at the beginning of the 1990s to disappearing by the end of the 2000s, even turning negative at the lower end of the distribution. An exploration of potential mechanisms reveals a large prevalence of job mismatch at the lower end of the part-time wage distribution as well as rising differences in the distribution of job tasks between full- and part-time employment.
\end{abstract}

Keywords: part-time employment, female wages, selection into employment, quantile regression

*DIW-Berlin, pgallegogranados@diw.de. The author thanks Ghazala Azmat, Christoph Breunig, Peter Haan, Anna Hammerschmid, Jean-Marc Robin, Katharina Wrohlich as well as seminar participants at the SAE meetings 2017, VfS 2018, EALE 2018 and DIW internal seminars for valuable comments, and Blaise Melly for sharing his programming code on the changes-in-changes model with covariates. The author thankfully acknolewdges financial support from the German Research Foundation (DFG SPP 1764). Any remaining errors are mine. 



\section{Introduction}

Part-time work has undergone a major expansion in many labor markets during the last decades (OECD 2016). At the same time, full- and part-time hourly wages have increasingly diverged, leading to an ever-increasing raw part-time wage penalty (OECD 2010). This paper explores to what extent this gap - which largely varies over the wage distribution - reflects the different observable and unobservable characteristics of individuals (and their jobs) engaging in full- or part-time employment and to what extent full- and part-time employment yield different returns to the same skills. As both channels entail potentially different policy implications and are likely to differ over the wage distribution, this analysis sheds new light on a phenomenon that affects a large and increasing share of the labor force. Furthermore, as most part-time employees are female, new insights on the part-time wage gap may contribute to the debate on the gender wage gap (Manning and Petrongolo 2008, Bowlus and Grogan 2009, Mumford and Smith 2009, Goldin 2014, Blau and Kahn 2017).

Existing literature focuses on estimating the average effect of part-time work on wages, controlling for several factors such as individuals' labor market characteristics or occupational choices (Aaronson and French 2004, Hirsch 2005, Manning and Petrongolo 2008, Connolly and Gregory 2009 and Paul 2016 to cite a few). While most studies find a small or no average wage effect of part-time employment among women, this can differ across the distribution. In fact, the literature shows that the effect of the returns to skill, selection into employment and institutional factors on wages can strongly vary over the wage distribution, and even more so in the prevailing context of rising wage inequality and female labour force participation (see DiNardo et al. 1996, Blundell et al. 2007, Dustmann et al. 2009, Arellano and Bonhomme 2017 and Biewen et al. 2018 among others). Therefore, this paper goes beyond the analysis of average wage effects of part-time employment and analyses the part-time wage gap across the wage distribution. The contribution of this paper is twofold: First, I present a measure of corrected female ${ }^{1}$ part-time wage gap across the wage distribution and over time that isolates differences in the wage structures of full- and part-time employment from composition effects of the two groups. Secondly, I estimate the magnitude of female sample selection into the two kinds of employment across the wage distribution and over time.

The empirical strategy follows a two-step procedure. First, I estimate selection-corrected female wage distributions for full- and part-time employment. To this end, I extend an imputation-based method to correct for sample selection issues developed by Melly and Santangelo (2014, 2015), which is based on Athey and Imbens (2006)'s changes-in-changes model. By imposing the timeinvariance of the unobservables conditional on the observables, the authors impute non-realized wages that account for both observable and unobservable characteristics of individuals. For the analysis at hand, I exploit the fact that many women in Western economies work both full- and part-time at some point in their lives (see e.g. Connolly and Gregory 2010 for the UK or Paul 2016 for Germany) to gain information on their person-specific unobservable in both kinds of employment. Through this procedure, which explicitly allows for individual's unobservables to differ in full- and part-time employment, I identify both a full- and a part-time wage for each

\footnotetext{
${ }^{1}$ It would be interesting to carry out the empirical analysis for men too, as the data also reveals a part-time wage gap for male employees. Unfortunately, this is not feasible because there are too few observations in the data of men working part-time in Germany over this time period.
} 
person-year observation in the sample, regardless of her actual (non-)employment status. For those women who I do not observe working in both kinds of employment, I need an additional assumption on their unobservables. The resulting full- and part-time wage distributions are, by definition, selection-corrected, as they rely on the entire sample. In a second step, I decompose the raw part-time wage gap across the wage distribution into three components: differences in the wage functions of full- and part-time employment, which I refer to as the corrected part-time wage gap, the magnitude of selection into full-time employment, and the magnitude of selection into part-time employment. This is similar to the decomposition procedure for distributions suggested by Machado and Mata (2005) and Chernozhukov et al. (2013), with the particularity that the required counterfactual distributions - in this case selection-corrected full- and part-time wage distributions - rely on the same underlying sample and are obtained following the model of Melly and Santangelo (2014), as explained in step one.

For the empirical analysis in this paper, I use the German Socio-Economic Panel (GSOEP), a rich longitudinal dataset with detailed information on individuals' earnings and working hours. I restrict the sample to prime-age women residing in West Germany and focus on the 1990 to 2009 period, two decades during which part-time employment dramatically expanded and the raw part-time wage gap widened across the entire distribution.

The paper includes several important findings. First, the data shows that the raw part-time wage gap increased at all points of the distribution over time. Evaluated at the median wage, the raw part-time wage penalty amounted to 10 log-points by the beginning of the 1990 s, a figure that almost doubles ten years later. The raw gap is the highest at the bottom of the wage distribution and steeply decreases with wages - even turning into a premium at the very top of the distribution in the 1990s. Over time, the decreasing profile of the raw gap with respect to wages flattens out somewhat, which results from strong wage compression at the upper half of the part-time distribution. In addition, the data reveals that, over time, part-time employment has gained prevalence in the low-wage sector while full-time employment has increased its prevalence in the high-wage sector. The results on the corrected part-time wage gap also indicate a large variation over the distribution and over time. Nonetheless, a common finding over time is the existence of a persistent corrected part-time penalty at the bottom end of the distribution, which cannot be ascribed to composition effects between full- and part-time employment. This is a new insight, which - combined with corrected premia at the top of the distribution - reconciles the current findings with most existing literature, according to which female average part-time penalty vanishes (or becomes very small) once it is controlled for individual's labor market characteristics or occupational choices. Otherwise, the corrected gap mimics the decreasing profile of the raw gap, albeit at a lower level. The flattening trend observed for the raw gap is even stronger in terms of the corrected gap, which by the end of the 2000s equals zero for almost half of the wage distribution. This implies that, in the late 2000s, differences in the wage structures of full- and part-time employment no longer explain most of the raw gap. In fact, I find that opposite selection patterns into full- and part-time employment increasingly explain the widening of the raw part-time wage gap over time.

Second, my results indicate strong positive selection into full-time work at all points of the distribution - implying that women with high potential wages tend to select into full-time work much more often than women with lower potential wages. Further, the magnitude of positive 
selection into full-time employment increases over time. On the contrary, selection into part-time employment displays a structural break from the end of the 1990s to the beginning of the 2000s, turning from positive to null - or even negative at the bottom of the distribution. This is a new insight, which is backed by the findings of Biewen et al. 2018 on the basis of German administrative data - which suggest negative selection into part-time employment - and Carrillo-Tudela et al. 2018, which ascribe the rise in female part-time employment (of individuals with low potential earnings) to the comprehensive labor market reforms implemented from 2002 onwards in Germany.

Third, in terms of underlying mechanisms, I show that there is a large gap between full- and parttime employment in terms of the (in)adequacy of individuals' jobs with respect to their previous training at the lower part of the distribution and that this gap decreases along the wage distribution but rises over time. I show that the job/training mismatch is associated with lower wages and that it is far more prevalent among low-skilled women and long non-market employment spells.

Moreover, an analysis of jobs main tasks reveal that the rise in non-routine cognitive tasks for female employees in Germany - identified as factor contributing to the rise in women's relative (full-time) wages over time (Spitz-Oener, 2006 and Black and Spitz-Oener, 2010) - has happened exclusively in the full-time sector. The distribution of main tasks in part-time employment has been relatively stable over the 1990-2009 period, with a light increase in non-routine manual tasks combined with a small decrease in routine cognitive tasks. As a result, the differences in the distribution of main tasks between full- and part-time employment have grown over time, suggesting an increase in job segregation among the two kinds of employment.

From the policy perspective, priority should be placed on reducing constraints for women who wish to engage in full-time work. These can be very different in nature, such as inadequate fulltime childcare arrangements, disincentives in the tax system - especially for second earners in joint taxation regimes - as well as difficulties to return to full-time employment after a phase of parttime employment, a phenomenon commonly known as the part-time trap. Furthermore, policies toward lifelong learning could contribute to decrease the prevalence of job/training mismatch among women with low skills and/or long non-market employment phases in their biographies.

This paper contributes to the existing literature on the effect of part-time employment on wages, which can be classified into three big strands according to its methodology: studies that use cross sectional data - often accompanied by decomposition exercises; analyses that are based on panel estimators of wage equations; and joint estimations of hours and wage equations.

Within the first strand, Blank (1990) is the first to produce estimates on the part-time pay penalty controlling for individuals' skills and sample selection; she finds substantial penalties for the United States in the late 1980s. Manning and Petrongolo (2008) estimate a variety of models and find that differing worker characteristics in the full- and part-time group as well as growing occupational segregation and rising wage inequality practically explain the totality of the observed rising part-time wage gap in the UK between 1975 and 2001. Bardasi and Gornick (2008) and Matteazzi et al. (2014) carry out cross-country studies on the average wage effects of part-time work and find occupational segregation to be a major determinant of the observed part-time pay penalty in most countries. In all these studies, sample selection is taken care of through the Heckman Two-Stage Model (Heckman 1979) and the chosen exclusion restrictions are based on household characteristics such as - but not limited to - marital status or number of children.

The next strand of the literature analyses the wage effects of part-time work by estimating fixed- 
effects wage models. In such models, the average effect of part-time work on wages is identified by the wage changes of individuals transitioning between full- and part-time status relative to the wage changes of individuals who stay in each type of employment. This paper's methodology is closest to this strand, as it also relies on a person fixed-effect assumption - although arguably with two advantages: exploiting the longitudinal dimension of the data allows including a larger share of individuals in the sample (thereby reducing its selectivity) and the person fixed effect is allowed to differ in full- and part-time employment. Hirsch (2005) finds a very small penalty for women in the United States once he controls for individuals' and job skills, whereas Booth and Wood (2008) find a female part-time premium for Australia. Fernández-Kranz and Rodriguez-Planas (2011) estimate a corrected part-time pay penalty for women in Spain and distinguish by their type of contract. Connolly and Gregory (2009) and Fouarge and Muffels (2009) also look at the long-term consequences on part-time work on wages and find long-term earnings losses for all countries under study.

The third group of papers takes into account the potential endogeneity between working hours and wages by conducting joint estimations of hours and wage equations. Aaronson and French (2004), making use of an old-age part-time social security rule in the United States as exclusion restriction, find a part-time penalty for men but not for women. Paul (2016), using exclusion restrictions from the German institutional context, distinguishes between short- and long-hours part-time work and finds a female part-time penalty on current wages for the first group but not for the latter. Wolf (2002), who uses exclusions restrictions based on household characteristics and labor demand, also finds a wage penalty for short-hours part-time employment in Germany.

Finally, this paper also relates to the literature on selection into employment and its effect on female wages, with its origins in the seminal works of Roy (1951), Gronau (1974), and Heckman (1979). Most closely, this paper builds upon the work of Melly and Santangelo (2014), who suggest an econometric method to account for changes in selection into employment over time and across the wage distribution, and use it to analyze the evolution of the gender wage gap in the US. An alternative to correct for sample selection from a distributional perspective has also been proposed by Arellano and Bonhomme (2017). Further work within this strand includes Mulligan and Rubinstein (2008), who show that the sign of selection into employment for women in the US changed from the 1970s to the 1990s and point to the role of wage inequality for the evolution of selection into employment and women's relative wages. Olivetti and Petrongolo (2008) show the importance of accounting for selection into employment for interpreting the variation of the gender wage gaps across European countries. For Germany, Biewen et al. (2018) find an increasingly positive selection into full-time employment by women between 1985 and 2010, relating this phenomenon to the rise in female wage inequality.

The paper is structured as follows. Sections 2 and 3 cover the empirical strategy and describe the data. Next, Section 4.1 presents evidence on the raw part-time wage gap across the distribution and over time and discusses it in the context of dramatic changes in the distribution of female wages. Section 4.2 discusses the results of the imputation of non-realized full- and part-time wages. Section 4.3 presents the results on the corrected part-time wage gap and the magnitude and evolution of selection into full- and part-time employment. Section 4.4 discusses potential mechanisms underlying my findings. Lastly, Section 5 concludes and draws policy recommendations. 


\section{Empirical strategy}

In this section I discuss the empirical strategy for deriving a measure of the part-time pay gap that isolates the wage effect of part-time employment while controlling for different selection of individuals into full- and part-time employment. Section 2.1 presents formally the concepts used throughout the paper. Section 2.2 describes Melly and Santangelo (2014, 2015)'s imputation method for recovering non-realized wages and its extension to the study of the part-time wage gap. Last, Section 2.3 discusses the specification of the conditional wage model used for the imputations.

\subsection{Corrected part-time wage gap and selection-corrected wage distributions}

In the following, I denote $X_{t}^{F T}, X_{t}^{P T}$, and $X_{t}^{O W}$ to be the joint distribution of human capital variables at time $t$ entering the wage model for three different subsamples: individuals working full-time, working part-time, and those who are out-of-work. The joint distribution of human capital variables for the whole sample is denoted $X_{t}=\left\{X_{t}^{F T}, X_{t}^{P T}, X_{t}^{O W}\right\}$. The distributions of $\log$ hourly wages for full- and part-time employment are referred to as $W^{F T}$ and $W^{P T}$, respectively. Throughout the paper $F(\cdot)$ denote unconditional cumulative density functions and $\tau$ stands for the unconditional rank in a given inverse cumulative function. The observed full- and part-time log wage distributions, $F_{W_{t}^{F T}}$ and $F_{W_{t}^{P T}}$, are only defined for individuals actually working full- and part-time with characteristics $X_{t}^{F T}$ and $X_{t}^{P T}$, respectively.

On the contrary, $\widehat{F}_{W_{t}^{F T}}$ and $\widehat{F}_{W_{t}^{P T}}$ are both defined for all individuals in the sample and consist of observed (realized) as well as imputed (non-realized) log wages. $\widehat{F}_{W_{t}^{F T}}$ and $\widehat{F}_{W_{t}^{P T}}$ are selectionfree by definition, as for each woman in the sample both a full- and a part-time wage is imputed, whenever one (or both) of them are not realized. This builds on the idea that sample selection issues can be controlled for once a wage rate for every individual in the sample - especially those individuals for whom a wage is not observed - is meaningfully imputed (see Neal (2004), Blau and Kahn (2006), and Olivetti and Petrongolo (2008) for earlier imputation-based approaches to control for sample selection issues).

Following this notation, the raw part-time wage gap at percentile $\tau$ and time $t$ can be expressed as the difference between the observed full- and part-time log wage distributions:

$$
G_{\text {raw }}(\tau, t)=F_{W^{F T}, t}^{-1}(\tau)-F_{W^{P T}, t}^{-1}(\tau)
$$

The corrected part-time wage gap is defined by the difference between the selection-corrected $\log$ wage distributions for full- and part-time work in a given year $t, \widehat{F}_{W^{F T}, t}$ and $\widehat{F}_{W^{P T}, t}$. Because these two distributions apply to the same underlying population with identical joint distribution of human capital variables, any difference between the two is due to the differing wage structures of full- and part-time employment:

$$
\widehat{G}_{c o r r}(\tau, t)=\widehat{F}_{W^{F T}, t}^{-1}(\tau)-\widehat{F}_{W^{P T}, t}^{-1}(\tau)
$$

Note that by adding and subtracting equation 2 to equation 1, and rearranging the terms, the raw part-time wage gap can be also expressed $\mathrm{as}^{2}$ :

${ }^{2}$ This can be understood as a usual decomposition exercise in the spirit of Oaxaca (1973) and Blinder (1973), or its quantile equivalent proposed by Machado and Mata (2005), with a particular interpretation of the composition 


$$
G_{\text {raw }}(\tau, t)=\widehat{G}_{\text {corr }}(\tau, t)+\widehat{\operatorname{Sel}}^{F T}(\tau, t)-\widehat{\operatorname{Sel}}^{P T}(\tau, t)
$$

where $\widehat{\operatorname{Sel}}^{F T}(\tau, t)=F_{W^{F T}, t}^{-1}(\tau)-\widehat{F}_{W^{F T}, t}^{-1}(\tau)$ quantifies the magnitude of selection into full-time employment and $\widehat{S e l}^{P T}(\tau, t)=F_{W^{P T}, t}^{-1}(\tau)-\widehat{F}_{W^{P T}, t}^{-1}(\tau)$ the selection into part-time employment.

Equation 3 implies that the difference between the raw and the corrected gap can be explained in terms of sample selection into both types of employment. In terms of interpretation, this implies that in case of identical returns to skill in full- and part-time employment, $\widehat{G}_{\text {corr }}$ would then be zero and any observed difference between full- and part-time wages would only be due to composition effects of individuals selecting into each kind of work arrangement.

\subsection{Imputation of non-realized wages}

In the following I briefly describe the method proposed by Melly and Santangelo $(2014)^{3}$ and then proceed to its application to the study of full- and part-time wages.

Intuitively, Melly and Santangelo (2014) suggest to build subsamples with individuals who work in two given periods (group 0) and compare them to subsamples of individuals who only work in one of these two periods (group 1). The latter reveals information on their unobservables in the one period when they work, which is captured by their conditional rank in the wage distribution. The evolution of wages of group 0 allows imputing group 1 a conditional wage that responds to the wage structure of the time when the imputation is required and that accounts for both observable and unobservable characteristics of the individuals.

This exercise is carried out for all possible combination of two survey years in the data, which I refer to as $\{k, l\}$. Group belonging according to the description above is captured by variables $G_{k l}$, each with realization $g_{k l} \in\{0,1\}$. The covariates entering the wage equation are captured in vector $\mathrm{X}$ and the unobservable component of wages in random variable $\mathrm{U}$.

Similar to other fixed effects panel methods, the identifying assumption behind this imputation method is the time-invariance of the unobservables conditional on the observables, i.e. $f_{U \mid T, G, X}=f_{U \mid G, X}$. In words, this implies that the distribution of unobservable characteristics that affect wages, such as innate ability or professional ambition, stay constant over time, conditional on observable characteristics such as education level and previous working experience. The specification of covariate vector $\mathrm{X}$ needs to capture as much variation in unobservable components as possible and, thus, is discussed separately in the next subsection.

Formally, Melly and Santangelo (2015) show that the conditional wage distribution of those individuals not working in time period $\mathrm{t}=\mathrm{k}$ but working in time period $\mathrm{t}=\mathrm{l}$ can be derived as:

$$
F_{W \mid g=1, t=k, x}^{-1}(\theta)=F_{W \mid g=0, t=k, x}^{-1}\left(F_{W \mid g=0, t=l, x}\left(F_{W \mid g=1, t=l, x}^{-1}(\theta)\right)\right)
$$

and individual wages conforming $F_{W \mid g=1, t=k, x}^{-1}(\theta)$ can be imputed as:

$$
\widetilde{w}_{i k l}=x_{i} \hat{\beta}_{g=0, t=k}\left(\int_{0}^{1} \mathbb{1}\left(x_{i} \hat{\beta}_{g=0, t=l}(u) \leq x_{i} \hat{\beta}_{g=1, t=l}(\theta)\right) d u\right)
$$

effect

${ }^{3}$ See Melly and Santangelo $(2014,2015)$ for details. The aim of this section is merely to sketch the imputation method proposed by the authors so as to make it understandable - for a thorough explanation of the model it is advised to refer to the original sources. 
where $\hat{\beta}_{g, t}(\theta)$ are the wage equation coefficients for conditional quantile $\theta$ coming from the estimated quantile regression processes. As each realized full- or part-time wage provides enough information to impute all non-realized wages of an individual, for employees who I observe working several years the imputation rule of expression 5 produces multiple imputations for each nonrealized wage. For these cases, Melly and Santangelo (2015) suggest to weight all available imputations so as to obtain final imputed wage for individual $i$ in year $k, \widetilde{w}_{i k}$ :

$$
\widetilde{w}_{i k}=\sum_{m=1}^{M_{i}} d_{i k m} \cdot \widetilde{w}_{i k l}
$$

where $M_{i}$ is the number of available imputations for a given $\widetilde{w}_{i k}$, different for each individual $i$, and $d_{i k m}$ is the weighting factor for each $\widetilde{w}_{i k l}$, so that $\sum_{m=1}^{M_{i}} d_{i k m}=1$.

In my particular application, I allow the wage structure of full- and part-time employment to differ from each other and carry out the imputation procedure separately for the two kinds of employment ${ }^{4}$. This is possible because a large share of women work both full- and part-time at some point in their lives and implies that only information from realized full-time (part-time) wages is used to impute full-time (part-time) wages. The identification of non-realised full-time wages requires the expression $f_{U^{F T} \mid T, G^{F T}, X^{F T}}=f_{U^{F T} \mid G^{F T}, X^{F T}}$ to hold, whereas the identification of nonrealised part-time wages requires $f_{U^{P T} \mid T, G^{P T}, X^{P T}}=f_{U^{P T} \mid G^{P T}, X^{P T}}$. Thus, not only the returns to observable characteristics are allowed to differ between full- and part-time employment but also the structure of unobservables is allowed to differ in both kinds of work arrangements. The later implies that particular individuals can have a different unobservable in the full- than in the parttime wage distribution. This is an important feature of this approach (and the main difference to a usual panel fixed-effect estimator), as there is no reason apriori to assume unobservable components stay constant in transitions from full- to part-time employment and viceversa. For instance, to the extent that individuals may choose to work part-time in order to combine market with non-market work duties, it is possible that individuals are willing to exchange wage losses for greater flexibility. Alternatively, certain individuals may be only willing to return to full-time employment if this represents a substantial wage increase. Furthermore, this approach is agnostic to whether wage-hours offers are tied or, alternatively, individuals may have leeway in choosing their working hours given a fixed wage.

Thus, group belonging is captured by variables $G_{k l}^{F T}$ and $G_{k l}^{P T}$ with realization $g_{k l}^{F T} \in\{0,1\}$ and $g_{k l}^{P T} \in\{0,1\}$ for all $\{k, l\}$, respectively. The algorithm in equation 5 is applied separately for fulland part-time wages. Given the high computational burden and the relatively small size of the estimation subsamples in the empirical application, I use a slightly modified imputation algorithm:

$$
\begin{aligned}
& \widetilde{w}_{i k l}^{F T}=x_{i} \hat{\beta}_{g^{F T}=0, t=k}\left(\int_{0}^{1} \mathbb{1}\left(x_{i} \hat{\beta}_{g^{F T}=0, t=l}(u) \leq \bar{w}_{i, t=l}^{F T}\right) d u\right) \\
& \widetilde{w}_{i k l}^{P T}=x_{i} \hat{\beta}_{g^{P T}=0, t=k}\left(\int_{0}^{1} \mathbb{1}\left(x_{i} \hat{\beta}_{g^{P T}=0, t=l}(u) \leq \bar{w}_{i, t=l}^{P T}\right) d u\right)
\end{aligned}
$$

where $\bar{w}_{i, t=l}$ is the observed wage for person $i$ in $t=l$ and replaces its estimated equivalent $x_{i} \hat{\beta}_{g=1, t=l}(\theta)$ in expression (5) above.

\footnotetext{
${ }^{4}$ See Ermisch and Wright (1993) for a discussion of reasons why full- and part-time employment are likely to present different wage structures.
} 
The main results, as presented in Section 4.3, use an unweighted average scheme, $d_{i k m}=\frac{1}{M_{i}}$, as suggested by Melly and Santangelo (2014). Other possibilities include a closest neighbor approach or a weighted average that penalizes wider distances between year $k$ and year $l$. The sensitivity of the results to different weighting schemes is examined in Appendix D.3.

With the imputation algorithms of equations 7 and 8, I can only recover non-observed wages for those individuals who I observe working both full- and part-time for at least one time period in the data. There are three groups for whom this is not possible: those who I never observe working full-time, those who I never observed working part-time, and those who I never observe working at all.

For these individuals, I apply a different imputation rule than the one described above, which I refer to as median imputation rule. In particular, I predict wages for them by means of the median conditional quantile coefficients estimated on the most suitable distribution. ${ }^{5}$ Missing fulltime wages for women who I do not observe working full-time are filled with predictions based on conditional quantile regression coefficients from either $Q_{0.5}\left(\widetilde{w}_{i t}^{F T} \mid X_{t}^{P T}\right)=x_{i t}^{\prime} \beta_{t}(0.5)$ if at period $t$ the individual was working part-time or from $Q_{0.5}\left(\widetilde{w}_{i t}^{F T} \mid X_{t}^{O W}\right)=x_{i t}^{\prime} \beta_{t}(0.5)$ if she was out-of-work. In both cases, $\widetilde{w}_{i t}^{F T}$ stands for full-time wages imputed according to the main model as captured by Equation 7. Non-realized part-time wages for women who have never worked part-time are filled equivalently. Whereas this alternative rule fully controls for observables (most importantly, actual full- and part-time working experience), unobservables are set to the median by assumption.

\subsection{Specification of the conditional wage model}

For the empirical strategy it is key to use a rich wage equation that accurately describes the wage process. The wage equation is estimated separately for the full- and the part-time wage distribution as a linear conditional quantile regression model (Koenker and Bassett, 1978):

$$
Q_{W}(\theta \mid x)=x \beta(\theta)
$$

The dependent variable, $w_{i t}$, is the natural logarithm of the hourly wage and the independent variables, $x_{i t}$, consist of an intercept, age, years of education, two indicator variables for intermediate and advanced degrees, actual full- and part-time working experience as well as interactions between the indicators and the experience variables. Age is included as a regressor in addition to years of education and experience since many women present spells of non-market work and those are the excluded category avoiding overidentification of the wage model. The goodness of in-sample fit of the conditional wage model is reported in Appendix B. Importantly, this specification allows for the returns to previous full- and part-time working experience to differ between the two and also to differ from each other in the wage functions of full- and part-time employment. This is an important feature as the literature finds that the returns to previous part-time experience are substantially lower than the returns to full-time experience (see, e.g. Blundell et al. 2016) ${ }^{6}$.

\footnotetext{
${ }^{5}$ This is a different imputation rule than the one suggested by Melly and Santangelo (2015) for such cases. Section D. 4 discusses possible alternatives.

${ }^{6}$ Besides the goodness of fit, the specification of the conditional wage model is crucial for the fulfilment of the identifying assumption. A flexible, rich specification clearly contributes to this end, although the econometric approach used in this paper restrains the choice of covariates in the wage model to characteristics observed for all women (including those out of work) in all survey years. As a result, variables such as current occupation and industry branch cannot be included in the wage model without further assumptions being made.
} 


\section{Data and Descriptive Statistics}

The empirical analysis is carried out on the basis of the German Socio-Economic Panel (GSOEP), a representative household survey that fulfills the two requirements of my empirical strategy: a longitudinal dimension combined with information on precise working hours and gross labor earnings (see Wagner et al. 2007 for details on the dataset). Administrative data (e.g. from the German Employment Institute) could be an alternative; however, the lack of precise information on individuals' working hours renders it unsuitable for this paper.

I restrict the analysis to 1990 through $2009 .{ }^{7}$ These are two decades in which part-time employment has dramatically expanded in West Germany and has reached a similar level to full-time employment. Furthermore, I also restrict the estimation sample to women aged 20 to 55 with residence in West Germany. Individuals in retirement, self-employment, the military, and disabled people are also excluded. Women pursuing education or on vocational training are kept in the estimation sample and are coded as non-working. Women who only participate one year in the GSOEP are dropped, since I require at least two observations per individual in order to be able to use this information in the imputation procedure. These sample restrictions leave us with a total of 6,448 female individuals in our sample. In terms of person-year observations, these represent a total of 71,044 observations oscillating between 2,700 to 4,700 observations per year (see column (1) in Tables A1 and A2 in the Appendix for the exact figures).

For the imputation procedure, the number of individuals who I never observe working either fullor part-time is important. During this time period, I observe both a full- and a part-time hourly wage for 24 percent of all women in the sample. For 31 percent of women, I only observe a fulltime wage, whereas for 26 percent I only observe a part-time wage. For the remaining 19 percent I do not observe any wage. In terms of person-year observations, for the 1990 to 2009 period the percentage of women having never worked in any of the two kinds of arrangement oscillates between 29 percent and 41 percent, depending on the year. ${ }^{8}$ The main reason for this relative large share is refreshment samples in the GSOEP. In fact, 60 percent of women report having worked both full- and part-time previously in their life, 26 percent say having worked only full-time, 9 percent only part-time and only 5 percent never worked at all. Therefore, the median imputation - which explicitly accounts for actual full- and part-time working experience - is a meaningful solution for this group, and allows to preserve the entire distribution of human capital variables contained in the raw data.

The dependent variable, the natural logarithm of the hourly wage, is constructed by dividing gross labor earnings over working hours in the main job. In order to minimize measurement error concerns, observations with a resulting hourly wage in the top and bottom $0.5 \%$ of each year's distribution are dropped. Hourly wages are inflated/deflated to 1995 prices based on CPI figures provided by the German Statistical Office. Figure 1 shows the resulting log hourly wage densities by full- and part-time employment, in which the existence of a raw part-time wage gap becomes evident.

\footnotetext{
${ }^{7}$ I finish the analysis in 2009 because in later years the share of women never observed working full-time substantially increases. This does not reflect a true phenomenon in the labor market but is a direct consequence of the new women joining the GSOEP as part of the refreshment samples introduced in years 2010 and 2011. Many of these women have small children and, although they report having worked full-time previously in their life, I do not observe them working full-time after 2009.

${ }^{8}$ See column (5) in Tables A1 and A2 in the Appendix for year-by-year figures.
} 
Figure 1: Observed Full- and Part-time Wage Densities
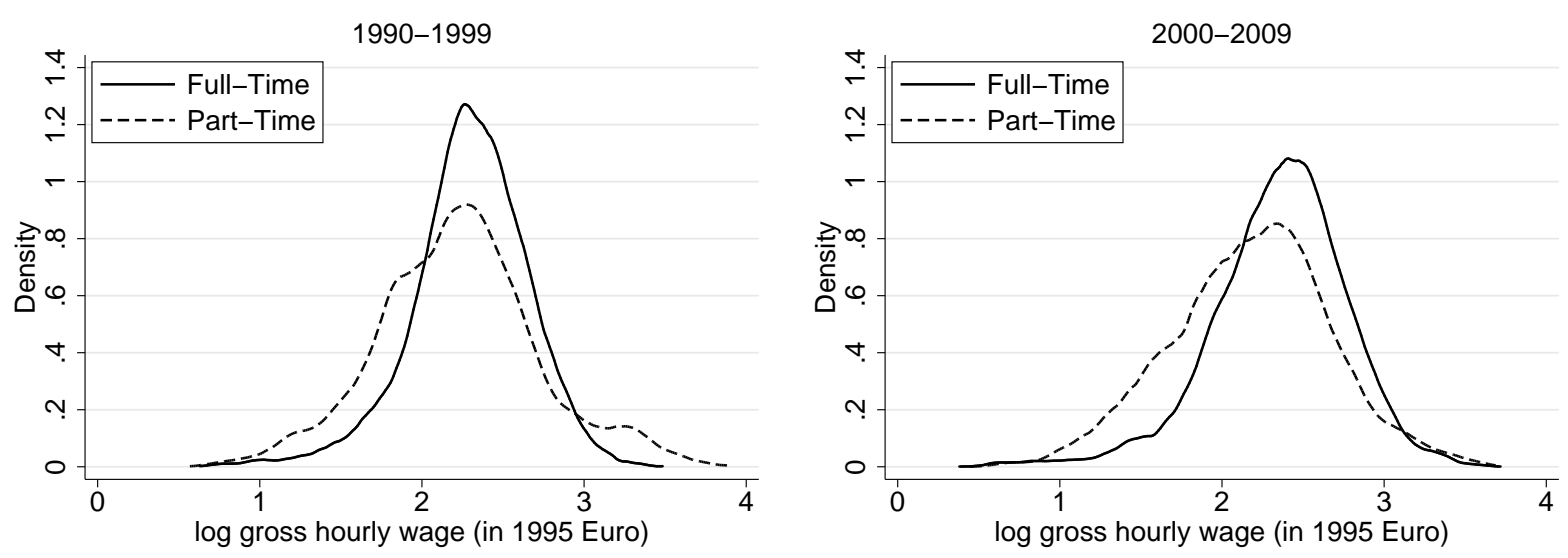

Source: SOEP v.33, own calculations

Working hours are defined as actual weekly working hours. In the main specification, women working more than 32 hours per week are coded as working full-time, while those working up to 32 hours are coded as working part-time. ${ }^{9}$ There is no comprehensive standard definition of part-time employment in Germany but most widely used definitions range from 30 up to 35 hours per week. Sensitivity analysis with alternative thresholds defining full- and part-time employment show that results are not driven by the chosen threshold (see Appendix D.1). Furthermore, I also replicate the results using contractual hours plus paid overtime instead of actual working hours (see Appendix D.2) and show that the results differ only minimally from the main ones and remain qualitatively the same. Women working less than 4 hours per week are coded as not working $^{10}$. Marginal employment, the term used for employment that pays below a given (low) monthly threshold established by law and for which alternative taxation and social security rules apply, is treated as part-time employment throughout the paper.

Figure 2 shows the distribution of working hours in full- and part-time employment, by wage quartile. As expected, the dispersion of working hours is larger in part-time employment. Shorthours part-time employment (often associated with marginal employment) concentrates in the lowest quartile of the distribution in the 1990s and expands to the lowest half of the distribution during the 2000s. In the full-time distribution, median working hours stay constant over the wage distribution and over time at approximately 40 hours per week, although the dispersion of working hours rises somewhat in the 2000s.

Descriptive statistics on the human capital variables entering the wage model are reported in Table 1 separately by full-time, part-time and out-of-work status. ${ }^{11}$ The three groups present large differences in terms of human capital, thereby anticipating substantial, time-varying composition effects between the subsamples, in particular with regard to education. Thus, while in the 1990s average years of education of those in full- and part-time employment were very similar, in the 2000s the data reveals a difference of almost half a year. Importantly, in the 1990s differences

\footnotetext{
${ }^{9}$ The literature also explores statistically at how many hours the part-time penalty arises (see Averett and Hotchkiss 1996), but this is outside the scope of this paper.

${ }^{10}$ Hourly wages corresponding to very low working hours appear to be unreasonably high in the GSOEP, hinting at measurement error issues.

${ }^{11}$ See Table A4 in Appendix for more detailed descriptive statistics (including shorter time periods, standard deviations and number of observations).
} 
Figure 2: Weekly working hours in full- and part-time employment, by wage quartile

(a) $1990-1999$

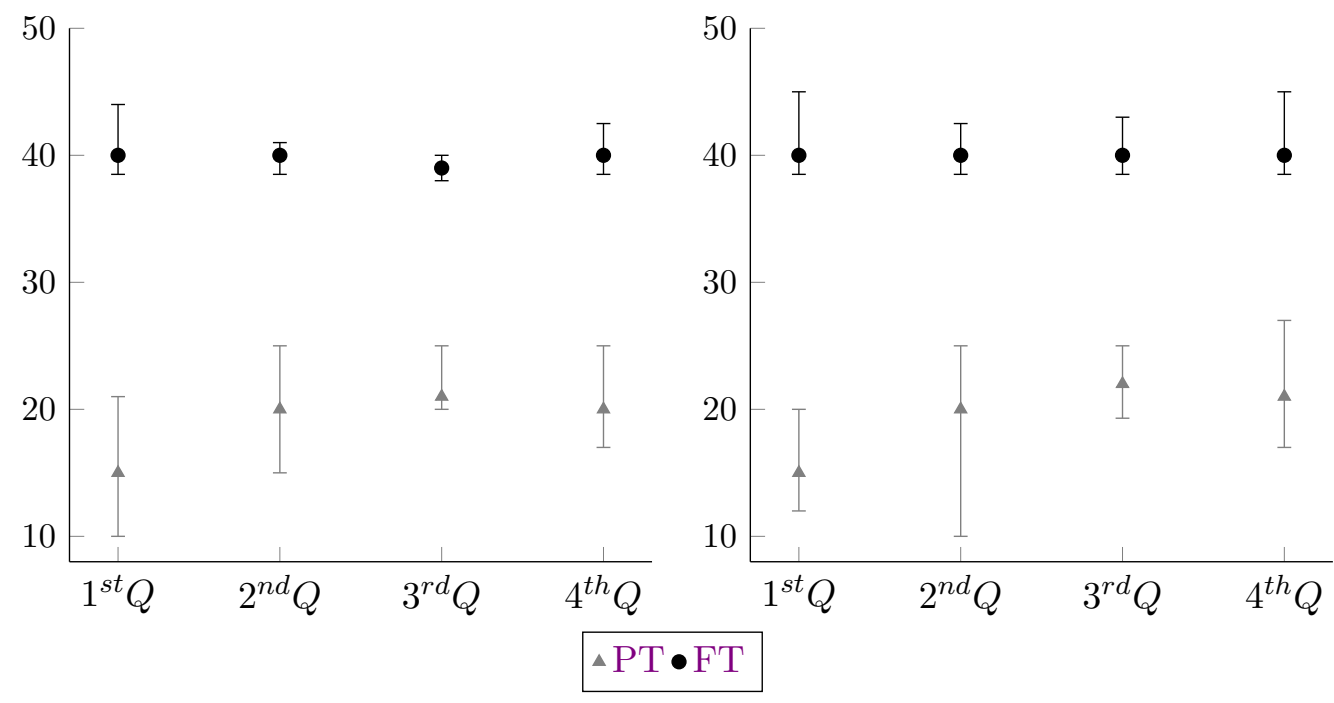

Source: SOEP v.33, own calculations

Notes: Markers represent median working hours; bulks represent $25^{\text {th }}$ and $75^{\text {th }}$ percentiles of working hours. The unit of the y-axis are actual weekly working hours and the x-axis depicts quartiles of the respective full- and part-time wage distribution.

in terms of educational achievement concentrated among women with basic and middle degrees, while the percentage of women with advanced degrees was very similar in the two groups. On the contrary, in the 2000s the share of women with advanced degrees working full-time had gone up by 8 percentage points, while the equivalent figure of those working part-time stayed constant at the 1990s level. Table 1 also reveals large differences in terms of actual full- and part-time working experience. Women who I observe working on a part-time basis have worked previously on average approximately 7 years on a full-time basis, a pattern that stays constant over the two decades. In constrast, women who I observe carrying a full-time job have already done so, on average, for over 11 years and display short part-time employment spells of one to two years.

Table 1: Human capital sample means, by full- and part-time status

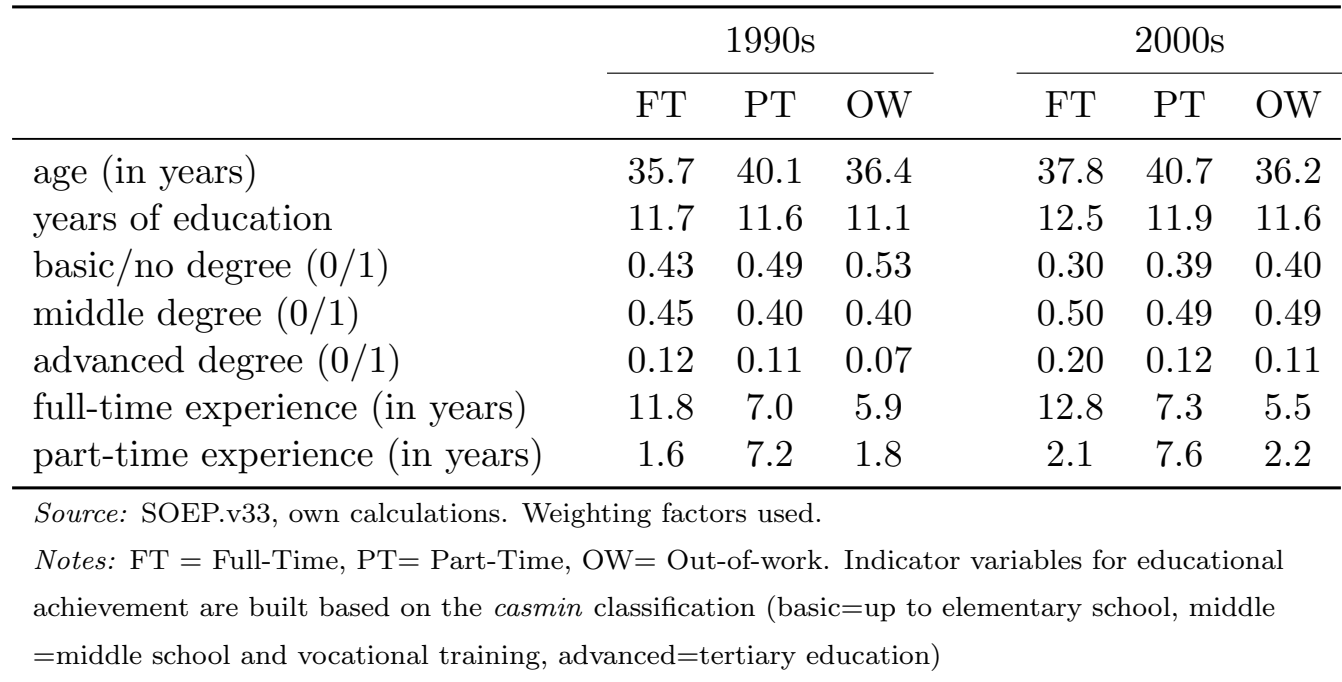


From a different perspective, Figure 3 shows that, although the rise in part-time employment has happened for women with and without children, part-time employment is much more prevalent among women with children.

Figure 3: Share of women working full-time, part-time and non working, by family status

$\longrightarrow$ Full-Time $\_$Part-Time No Work
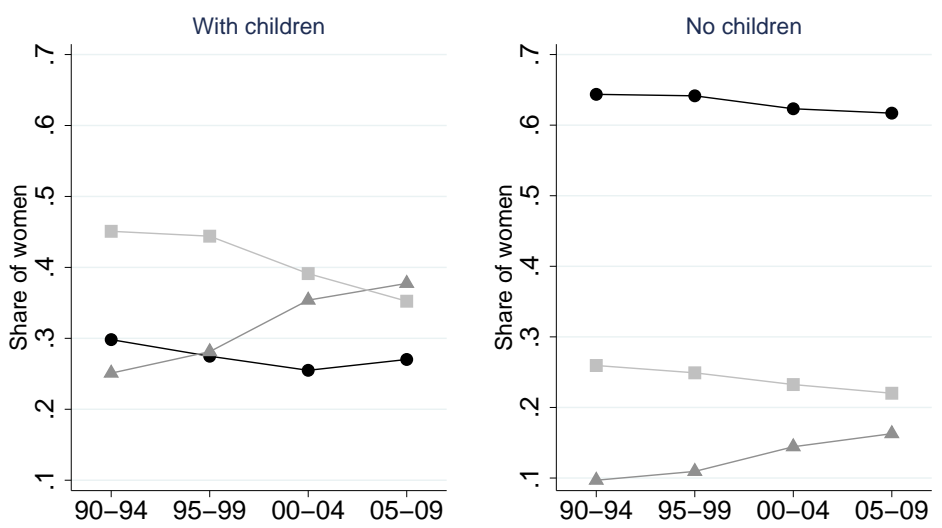

Source: SOEP.v33, own calculations.

\section{Results}

\subsection{Part-Time Employment and The Raw Part-Time Wage Gap}

This section describes the rise in part-time employment and the parallel evolution of the raw part-time wage gap.

Figure 4: Full- vs Part-Time Employment Rates

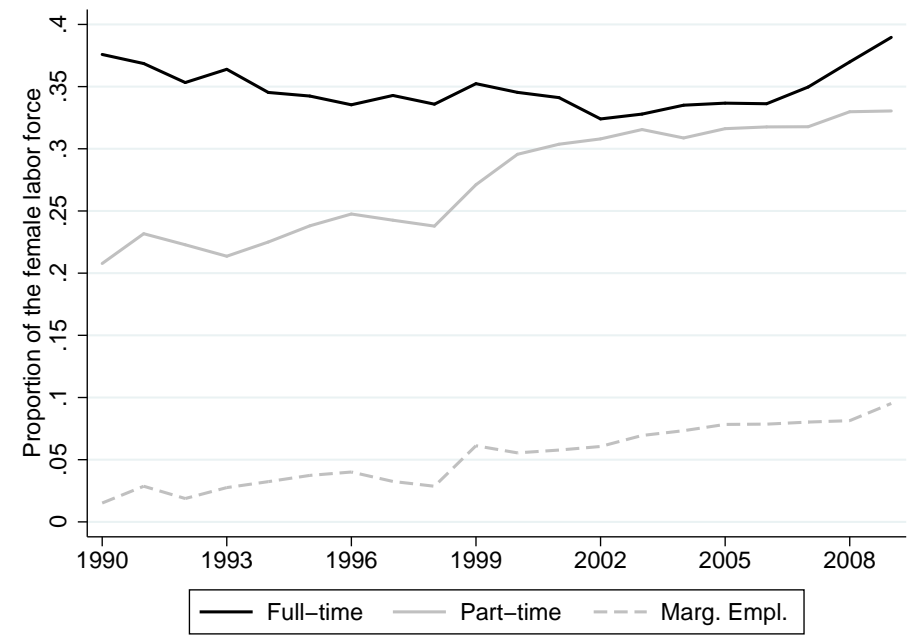

Source: SOEP v.33, own calculations

Notes: Marginal employment included in part-time employment.

The evolution of full- and part-time employment rates over time are shown in Figure 4. The 
full-time employment rate is quite stable around the 35 percent level, whereas the part-time employment rate has dramatically increased during the twenty years under study, approaching the level of full-time employment by the 2000s. Figure 4 also depicts the evolution of marginal employment over time (the dashed line in the graph), ${ }^{12}$ which accounts for every tenth part-time worker at the beginning of the 1990s and represents slightly more than every fourth part-time employee twenty years later.

The parallel evolution of the raw part-time wage gap is reported in Table 2. Given that gaps are computed as the difference between full-time log wages minus part-time log wages, positive figures imply part-time wage penalties whereas negative figures hint at a part-time wage premium. The raw part-time wage gap displays large variation across the distribution and has undergone substantial changes over time. The raw gap is the highest at the bottom of the wage distribution and steeply decreases with wages - in the 1990s even turning into a premium at the very top of the distribution. Evaluated at the median wage, the raw part-time wage penalty amounts to 10 log-points by the beginning of the 1990s, a figure that almost doubles ten years later. However, the biggest change over time occurs for the upper-end of the distribution, where a 12 log-point premium turns into a 10 log-point penalty over this twenty-year period.

Table 2: Raw Part-Time Wage Gap

\begin{tabular}{lcccc}
\hline & $\mathbf{1 9 9 0 - 1 9 9 4}$ & $\mathbf{1 9 9 5 - 1 9 9 9}$ & $\mathbf{2 0 0 0 - 2 0 0 4}$ & 2005-2009 \\
\hline$G_{\text {raw }}(\tau=.10)$ & .22 & .27 & .36 & .32 \\
$G_{\text {raw }}(\tau=.25)$ & .20 & .22 & .24 & .27 \\
$G_{\text {raw }}(\tau=.50)$ & .10 & .09 & .16 & .19 \\
$G_{\text {raw }}(\tau=.75)$ & .01 & .03 & .09 & .13 \\
$G_{\text {raw }}(\tau=.90)$ & -.12 & -.13 & .02 & .10 \\
\hline Source: SOEP.v33, own calculations. Weighting factors used. \\
Notes: Units are log-point differences between the full- and part-time inverse cumulative \\
wage distributions evaluated at several percentiles $\tau$ of the unconditional wage distribution.
\end{tabular}

The variation displayed across the distribution and over time hints at substantial differences in the evolution of full- and part-time wages over time. Therefore, Table 3 reports wage dispersion measures by full- and part-time status over time. Full-time wages are less dispersed than part-time wages throughout the whole period, but inequality within full-time wages has increased substantially from year 2000 onwards in a rather symmetric pattern between lower- and uppertail inequality. On the contrary, dispersion measures of part-time wage gaps, which are higher throughout, display a moderate increase in the second half of the 1990s but are otherwise stable for the complete time span. Remarkably, the stability of the $P 90-P 10$ measure for the part-time distribution over time results from the compression of the upper-half of the distribution and the dispersion of the lower-half of the distribution. Thus, the rise of a raw penalty on the top of the distribution as well as the slight flattening of the raw gap along the wage distribution seem to result from the combination of wage compression at the upper half of the part-time distribution

\footnotetext{
${ }^{12}$ Figure 4 only depicts individuals in marginal employment who exclusively work in such an arrangement. Individuals with a regular part- or full-time job additionally working in marginal employment are picked up by the part- or full-time lines. This is consistent with the definition of gross earnings used, which only takes into account the main job of each individual, and explains why the depicted figures are lower than official statistics on the overall number of people working in so-called Minijobs.
} 
with higher dispersion in the full-time distribution.

Table 3: Wage dispersion within full- and part-time employment

$1990-1994 \quad 1995-1999 \quad 2000-2004 \quad 2005-2009$

(A) Wage dispersion within part-time employment:

\begin{tabular}{lllll}
\hline Overall $(P 90-P 10)$ & 1.21 & 1.26 & 1.26 & 1.26 \\
Upper-tail $(P 90-P 50)$ & 0.63 & 0.63 & 0.58 & 0.57 \\
Lower-tail $(P 50-P 10)$ & 0.58 & 0.63 & 0.69 & 0.69 \\
\hline
\end{tabular}

(B) Wage dispersion within full-time employment:

\begin{tabular}{lllll}
\hline Overall $(P 90-P 10)$ & 0.86 & 0.86 & 0.93 & 1.04 \\
Upper-tail $(P 90-P 50)$ & 0.41 & 0.41 & 0.43 & 0.48 \\
Lower-tail $(P 50-P 10)$ & 0.46 & 0.45 & 0.49 & 0.56 \\
\hline
\end{tabular}

Source: SOEP.v33, own calculations. Weighting factors used.

Notes: Units are log-point differences between the inverse cumulative distributions evaluated at $P 10, P 50$ and $P 90$.

\subsection{Imputation of Non-Realized Wages}

Figure 5 summarizes the result of the imputation procedure ${ }^{13,14}$ and depicts the evolution over time of observed (solid lines), imputed (dashed lines) and selection-corrected (dotted lines) log hourly wages in full- and part-time employment at three selected points of the unconditional distribution $(\tau=.25 ; .5 ; .75)$.

Dotted lines in Figure 5 represent the selection-corrected wage distributions, which are made up of both observed and imputed wages, and are bound to lie between the two. The distance between the selection-corrected distribution and the observed one depends on the share of individuals requiring imputations as well as the difference in levels between imputed and observed wages. In the case of full-time employment, imputed wages are much lower than observed ones - hinting at strong positive selection into employment. For part-time employment, the selection-corrected distribution is much closer to the observed one and by the mid-2000s both are very similar.

The imputation results reveal important insights. Full-time imputed wages are lower than observed ones at all points of the distribution, which is consistent with the large differences found in terms of education and working experience between the subsamples working full-, part-time and out of work. Imputed part-time wages are closer to their observed counterparts than in the case of full-time employment. The reason for the smaller distance is that part-time imputations are carried out for two groups - those working full-time and those out-of-work - with large differences in terms of human capital, whose differences partially cancel out when regarded as one group. This is best illustrated in Figure 6, which graphically show imputations by in- and out-of-work status. In addition, the results displayed in Figure 6 suggest that, over time, the increasing variance in the returns to human capital investments is a phenomenon that takes place in the entire labor market regardless of the full- and part-time distinction. Thus, I find imputed part-time wages for those individuals who actually work full-time to be between 10 and $25 \log$ points higher than realized part-time wages (see lower panel of Figure 6).

\footnotetext{
${ }^{13}$ These imputation results correspond to using an unweighed average of multiple imputations (when available) and the alternative imputation rule presented in Section 2.2. A sensitivity analysis of the imputation results to these choices is provided in Appendix D.

${ }^{14}$ See Appendix $\mathrm{C}$ for a technical documentation of the imputation procedure.
} 
Turning now to part-time imputed wages, Figure 6 shows that these are lower than their realized counterparts but increase more steeply, so that during the 2000s they reach the level of observed part-time wages. The dynamics of imputed part-time wages are the result of three factors. First, imputed part-time wages for the sample working full-time display relative high growth over the entire period. This is consistent with the evolution of observed full-time wages, which also exhibits such a trend, and hints at the fact that high levels of human capital are also rewarded in the part-time wage structure. Second, imputed part-time wages for the out-of-work group display a certain convergence to observed part-time wages, especially in the lower half of the distribution. Third, over time the weight in the overall part-time imputation between the group working fulltime and the out-of-work group has evolved to the advantage of the full-time working group, as the out-of-work group represents a decreasing share of the overall female sample over time.

The imputations presented in Figure 6 entail imputed wages according to both the main model as well as the median imputation described in Section 2.2. Given the differences in human capital levels between the groups, the distribution of wages imputed with median coefficients necessarily differs from that of wages imputed according to the main model. Appendix D.4 explores to what extent differences are driven by observable characteristics and to what extent they are driven by the additional assumption on the unobservables of this group. The checks suggest that the results for the median are robust, while the additional assumption may have an effect on the magnitude (but not the sign) of the results at the two tails of the distribution. 
Figure 5: Observed, Imputed and Selection-Corrected Wage Distributions
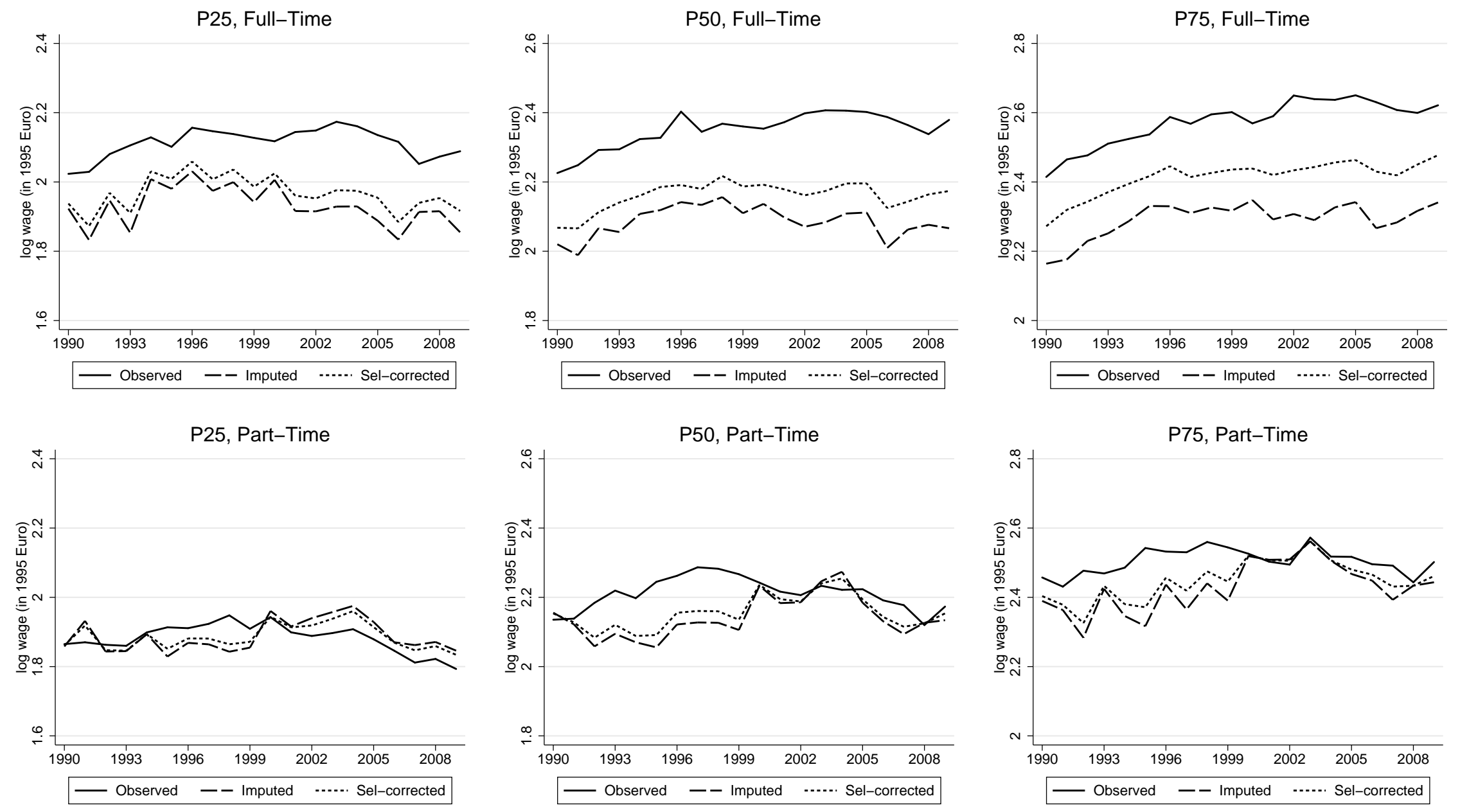

Source: SOEP v.33, own calculations. 
Figure 6: Imputations by full-time, part-time or out-of-work status
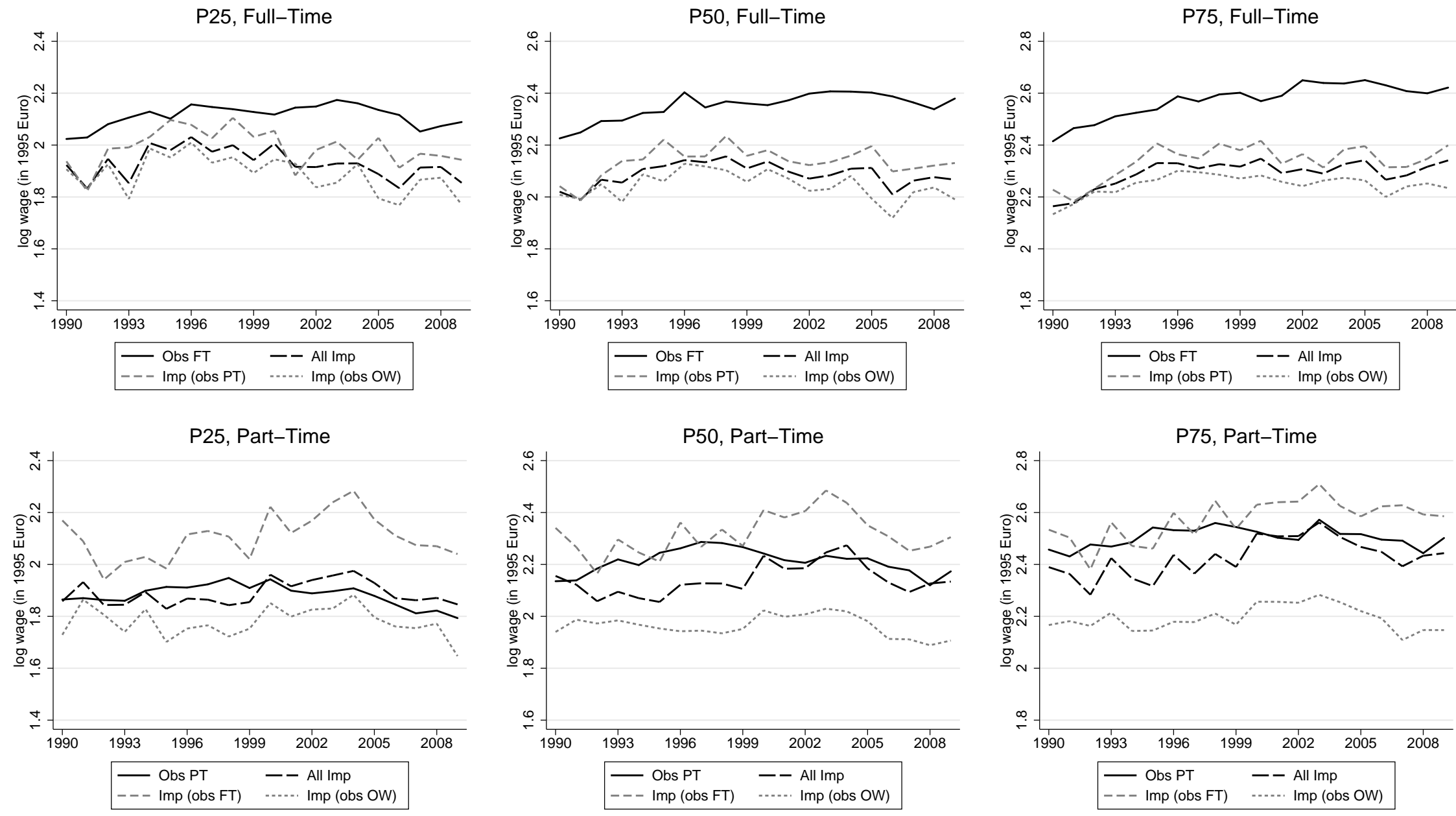

Source: SOEP v.33, own calculations. 


\subsection{Corrected Gap and Selection into Full- and Part-Time Employment}

Once non-realized full- and part-time wages are imputed, I have all the ingredients required to decompose the raw part-time wage gap into differences in the wage distributions - the corrected part-time wage gap - from differences in the selection patterns into full- and part-time employment.

Figure 7: Raw- vs Corrected Part-Time Wage Gap
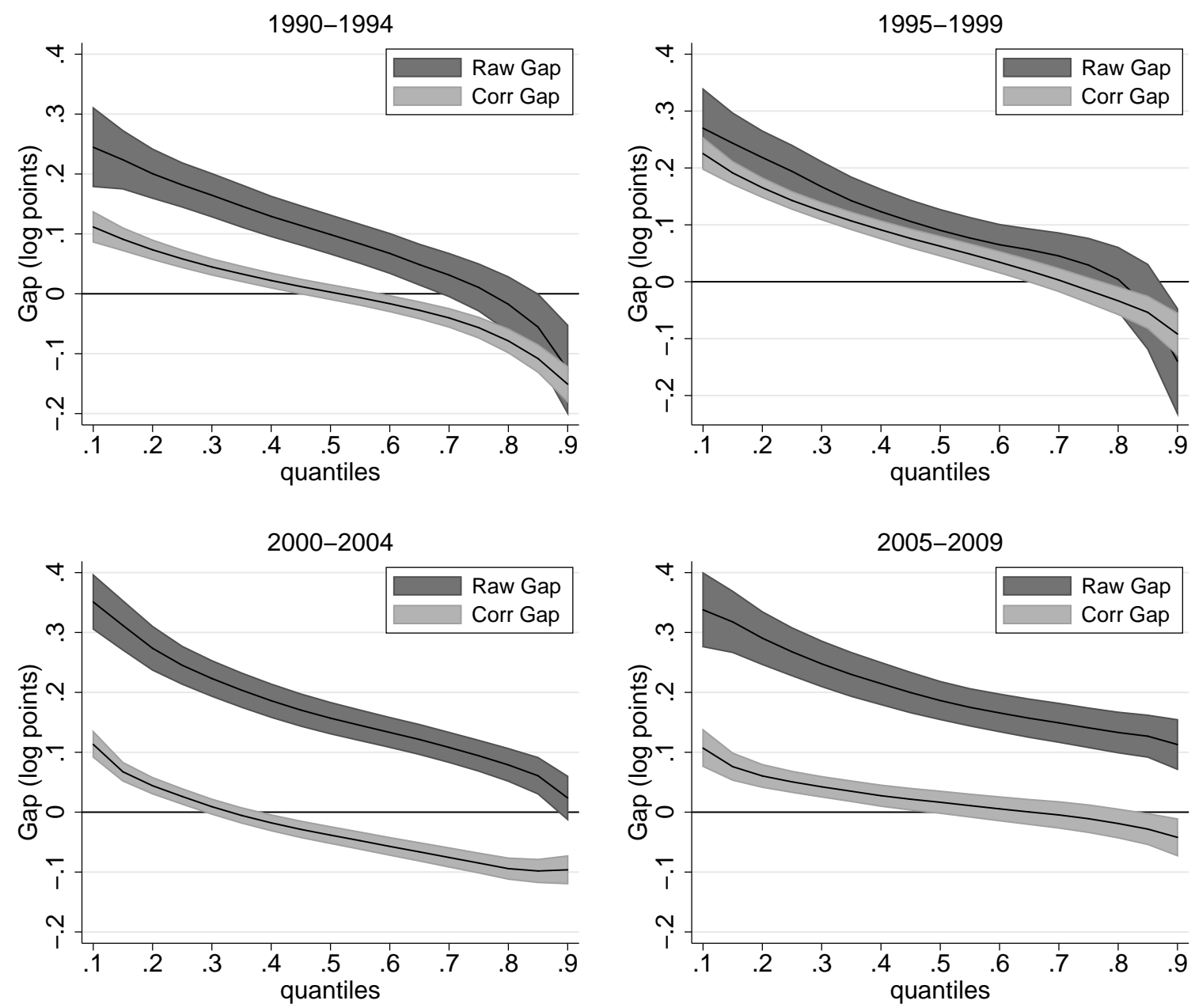

Source: SOEP v.33, own calculations

Notes: Shaded areas represent 95\% uniform confidence bands computed by bootstrap with 200 replications following Melly and Santangelo (2015). The x-axis refers to quantiles of the female log hourly wage distribution.

Results on the corrected part-time wage gap, $\widehat{G}_{c o r r}$, are displayed in Figure 7 together with the raw part-time wage gap, $G_{\text {raw }}$, for reference. Note that gaps are computed as the difference between full-time log wages minus part-time log wages, so that positive gaps in Figure 7 should be interpreted as part-time wage penalties whereas negative figures hint at a part-time wage premium.

The results on the corrected part-time wage gap, $\widehat{G}_{c o r r}$, can be summarized into three main messages. First, I find large variation of the corrected part-time wage gap across the distribution and over time, both in the form of penalties and in the form of premia. This finding is consistent with the view that part-time employment is a very heterogeneous phenomenon and reinforces the added value of choosing a distributional perspective.

Second, I find a corrected penalty at the lower end of the distribution, which persists over 
the twenty years under study and cannot be explained by composition effects of the subsamples working full- and part-time. This is a new insight that - combined with corrected premia at the top of the distribution - reconciles the current findings with most existing literature, according to which female average part-time penalty disappears (or becomes very small) once it is controlled for individual's labor market characteristics or occupational choices. In particular, my results at the median are compatible with Paul (2016), who finds for Germany, in the period 1984 to 2011, a negative average wage effect for short-hours part-time and a slight premium for long-hours part-time, and Fouarge and Muffels (2009), who find no effect of part-time work on current wages for the period 1994 to 2006. My results are also consistent with Wolf (2002), who finds a parttime penalty even after controlling for human capital characteristics for a data cross-section in 1995. The findings for the median are also in line with the more broader, international context, in which most studies find very small or no penalties for female part-time work once they control for individuals' labor characteristics (see Aaronson and French 2004 and Hirsch 2005 for the US). But also corrected premia, as displayed for median wages in the period 2000-2004, are found in the literature previously (see, for instance, Booth and Wood (2008) who find a part-time wage premium for Australia and Mocan and Tekin (2003) who also identify a wage premium for parttime employees in the non-profit sector in the United States).

Third, my results show that differences between the corrected and the raw part-time wage gaps increase dramatically from the 2000 s onwards at all points of the distribution, implying that the explanatory power of different full- and part-time wage structures for the raw gap decreases over time. This is most evident in the results for the late 2000s, in which I find no evidence for the existence of a corrected wage gap for most of the upper half of the distribution - while the raw part-time penalty for the same time period ranges from 11 to $34 \log$-points (see Table 2). As differences between the two measures can be explained by different selection patterns into full- and part-time employment ${ }^{15}$, next I discuss the estimates on $\widehat{\operatorname{Sel}}^{F T}(\tau, t)$ and $\widehat{\mathrm{Sel}}^{P T}(\tau, t)$ over time and across the distribution.

The effect of sample selection on each of the two wage distributions can be summarized as the log-point difference between the observed and the selection-corrected full- and part-time log wage distributions at selected percentiles (see Figure 8). Given that the difference is specified as the observed distribution minus the selection-corrected one, positive (negative) values hint at positive (negative) sample selection into each type of work arrangement with respect to the entire population. ${ }^{16}$ Figure 8 (a) shows that the female full-time wage distribution is strongly positively selected at all points in the distribution. The selection effect at the median hourly wage takes on values around 15 to $21 \mathrm{log}$ points depending on the time period. This means that the observed median full-time wage is 15 to $21 \mathrm{log}$ points higher than it would be if the group working full-time would be representative for the female labor force. Throughout the complete time span under study, positive selection into full-time employment is found to be strongest in the middle of the distribution and weakest at the lower end of the distribution. Moreover, from 2000 onwards, I find increasing positive selection all points of the distribution. The rise appears particularly strong in the middle of the distribution. The pattern is very different for selection into parttime employment. During the 1990s, I find the upper half of the part-time wage distribution to be

\footnotetext{
${ }^{15}$ Recall expression 3, which implies $G_{\text {raw }}(\tau, t)-\widehat{G}_{\text {corr }}(\tau, t)=\widehat{\operatorname{Sel}}^{F T}(\tau, t)-\widehat{\operatorname{Sel}}^{P T}(\tau, t)$.

${ }^{16}$ Figures on the magnitude of selection into full- and part-time employment do not add to zero because each of them is computed with respect to the entire population instead of only the non-working population.
} 
increasingly positively selected, whereas for the lower end, the selection estimate is not statistically significant. In the 2000s, sample selection disappears for most of the part-time distribution and it turns substantially negative for the lower end of the distribution (at around 13 log points). In fact, the large negative selectivity at the lower end of the part-time wage distribution - together with the ever rising positive selection into full-time employment - explain most of the raw part-time wage gap at this point of the distribution.

Figure 8: Effect of sample selection

(a) Full-time Wage Distribution

(b) Part-time Wage Distribution

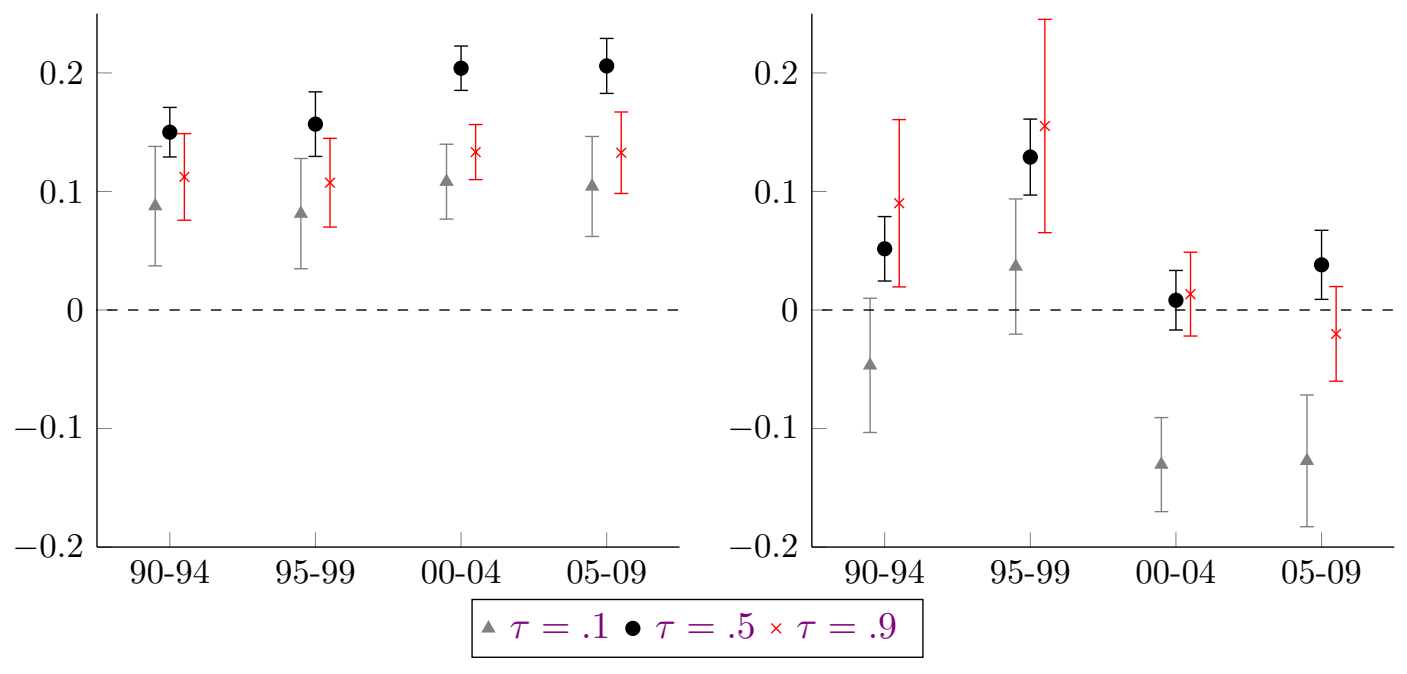

Source: SOEP v.33, own calculations

Notes: Bulks represent $95 \%$ uniform confidence bands computed by bootstrap (200 replications) following Melly and Santangelo (2015). The unit of the y-axis are log points and the x-axis depicts time.

The steady increase in positive selection into full-time employment is consistent with Mulligan and Rubinstein (2008)'s model, ${ }^{17}$ according to which selection into employment is expected to rise in times of rising wage inequality - even in the context of a constant employment rate. Rising female full-time wage inequality in the 1990s and 2000s in Germany is well documented in the literature (e.g. Dustmann et al. 2009) and newly so is rising positive selection into full-time employment (Biewen et al., 2018). In contrast, the magnitude of selection into part-time employment displays a substantial break from the end of the 1990s to the beginning of the 2000s, turning from positive to null - or even negative at the bottom of the distribution. This is a new insight that is backed by the findings of Biewen et al. 2018 on the basis of administrative data - which suggest negative selection into part-time employment - and Carrillo-Tudela et al. 2018, which ascribe the rise in female parttime employment (of individuals with low potential earnings) to the Hartz labor market reforms implemented starting in 2002.

Figure 9 shows full- and part-time employment rates over time by those human capital variables included in the wage model. The full-time employment rate rises with educational achievement and previous working experience, pointing at positive selection into full-time employment on these two

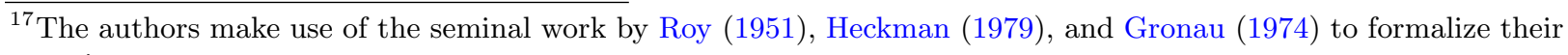
point. 
observable factors. ${ }^{18}$ Over time, Figure 9 reveals substantial changes in the full-time employment rate by educational achievement and age, but not working experience. Hence, the share of women working full-time conditional on having an advanced degree has increased around 10 percentage points while decreasing 5 percentage points for those women with an intermediate degree over the twenty years under study. This points at education as a main observable factor behind the increase in positive selection into full-time employment over time. In terms of age, the full-time employment rate is highest for the youngest category of women. However, from the beginning of the 1990s onwards, the full-time employment rate for this category decreased roughly 8 percentage points, amounting to $40 \%$ by the end of the 2000s. This decrease could be a consequence of the observed longer years of education for women, as this is the only age group for which nonemployment increased during the late 1990s. For all other age categories, the full-time employment rate displays a flat profile over time slightly higher than $30 \%$.

Contrary to the full-time employment rate, over time the part-time employment rate has risen strikingly homogeneously at all levels of the diverse human capital variables, with the exception of women with an advanced educational degree, for which it has stagnated. This is consistent with the finding that selection into part-time employment diminishes over time.

Next I turn to explore full- and part-time employment rates by unobservable characteristics, as summarized by individuals' conditional rank in the joint (full- and part-time) wage distribution. Results are reported in Figure 10, which plots the probability of working full- and part-time (conditional on working) over time, by rank in the overall female conditional wage distribution. ${ }^{19}$ The dashed lines in Figure 10 represent full- and part-time employment rates (conditional on employment) and serve as benchmark to evaluate the role of unobservables regarding the selection into full- and part-time employment. In the 1990s, working women were more likely to have a fulltime job than a part-time job regardless of their unobservables. This is shown by circle-marked lines lying above triangle-marked lines in Figure 10. However, women with both low- (below the $25^{\text {th }}$ percentile) and high- conditional ranks (above the $75^{\text {th }}$ percentile) were over-proportionately likely to work part-time, while women in the middle half of the distribution were over-proportionately likely to work full-time. Remarkably, in the first half of the 2000s, women with low ranks in the conditional distribution become 10 percentage points more likely to have a part-time job than a fulltime job (although, conditional on employment, full-time work was more common). Furthermore, selection bias for unobservables at the middle of the distribution has remained constant over time and selection on unobservables for women with high conditional ranks has disappeared over time (as can be seen by the marked lines coinciding with the dashed, benchmark lines).

To sum up, Figure 10 indicates that there is selection in factors other than human capital and that those have been evolving over time. Concretely, my findings suggest that individuals with low unobservables are over-represented in the part-time distribution, whereas individuals with middle unobservables are over-represented in the full-time distribution. Moreover, individuals with high unobservables were over-represented during the 1990s in the part-time distribution. In the 2000s, this is no longer the case and individuals with high unobservables are proportionally represented in each kind of employment.

\footnotetext{
${ }^{18}$ Figure 9 also shows that the level of the full-time employment rate decreases with age. However, due to the $\mathrm{u}$-shaped returns to age, no conclusion in terms of selection can be derived from this.

${ }^{19}$ See Chernozhukov and Hansen (2005) for a discussion of the interpretation of the conditional rank of an individual as a summarizing variable of her wage-relevant unobserved characteristics.
} 
Figure 9: Share of women working full-time, part-time and non working, by observable characteristics and over time

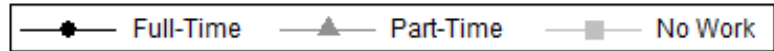

(a) Education
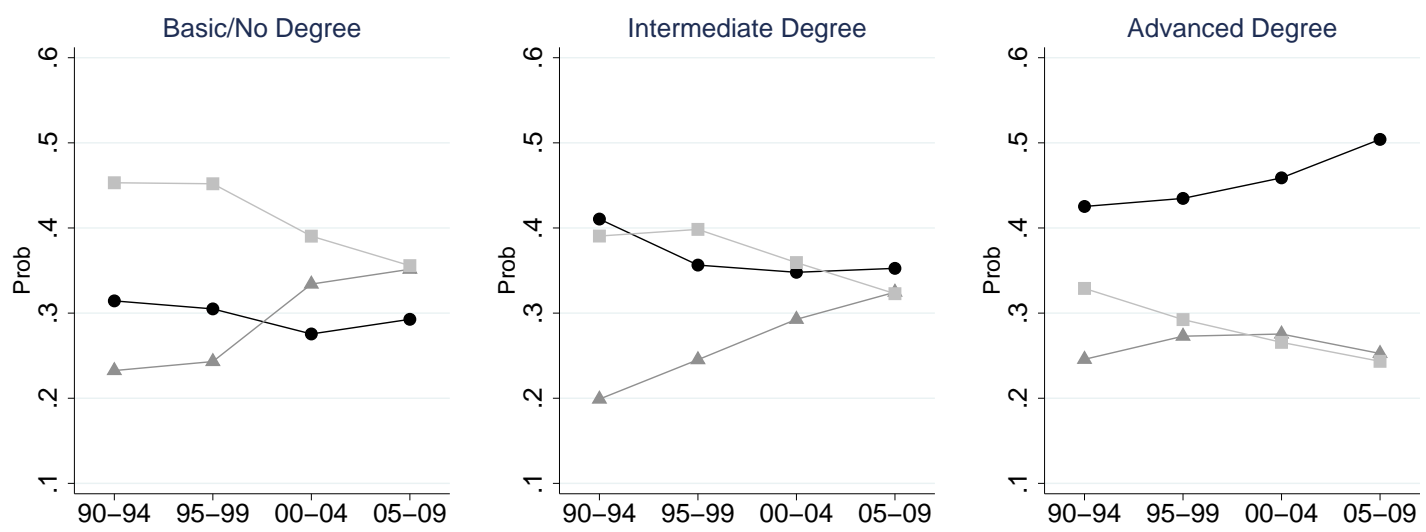

(b) Age
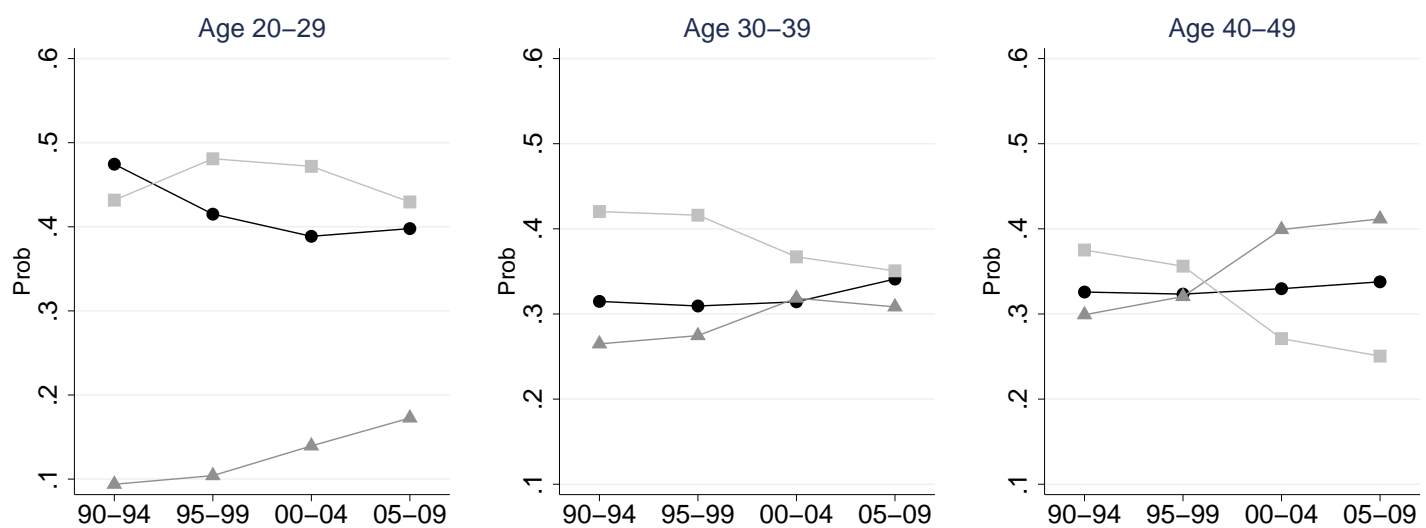

(c) Total Working Experience
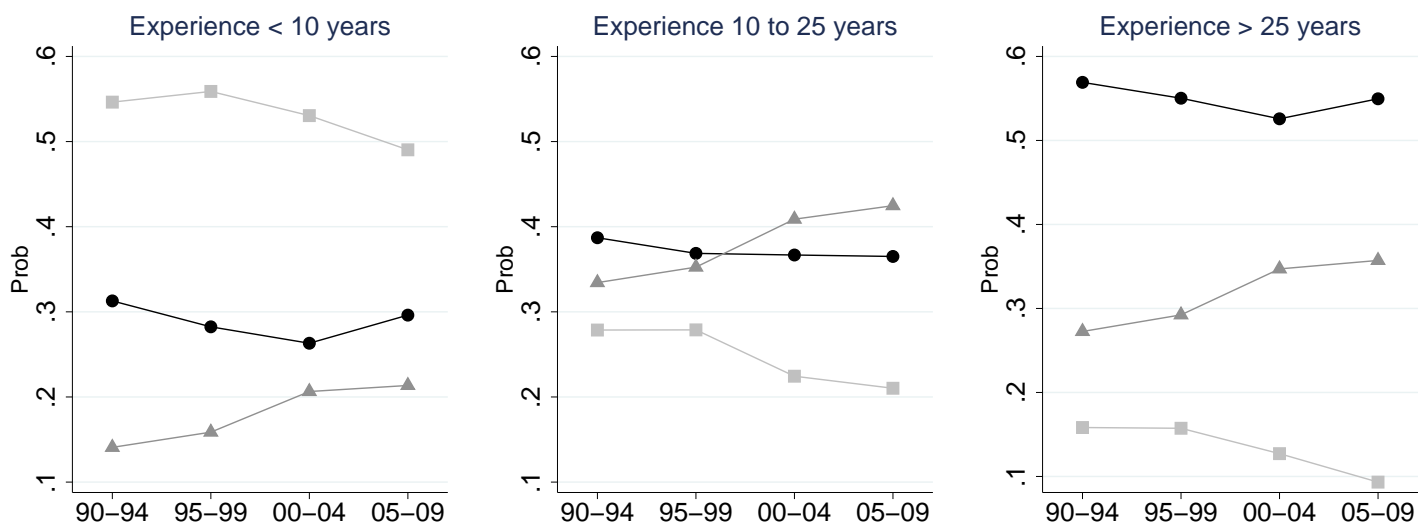

Source: SOEP.v33, own calculations.

Notes: Total working experience in Panel (c) consists of the sum of previous years of working experience in full-time, part-time and marginal employment with no further weighting. 
Figure 10: Probability of Working Full- or Part-Time, by conditional rank

$\longrightarrow \bullet$ Full-Time Part-Time
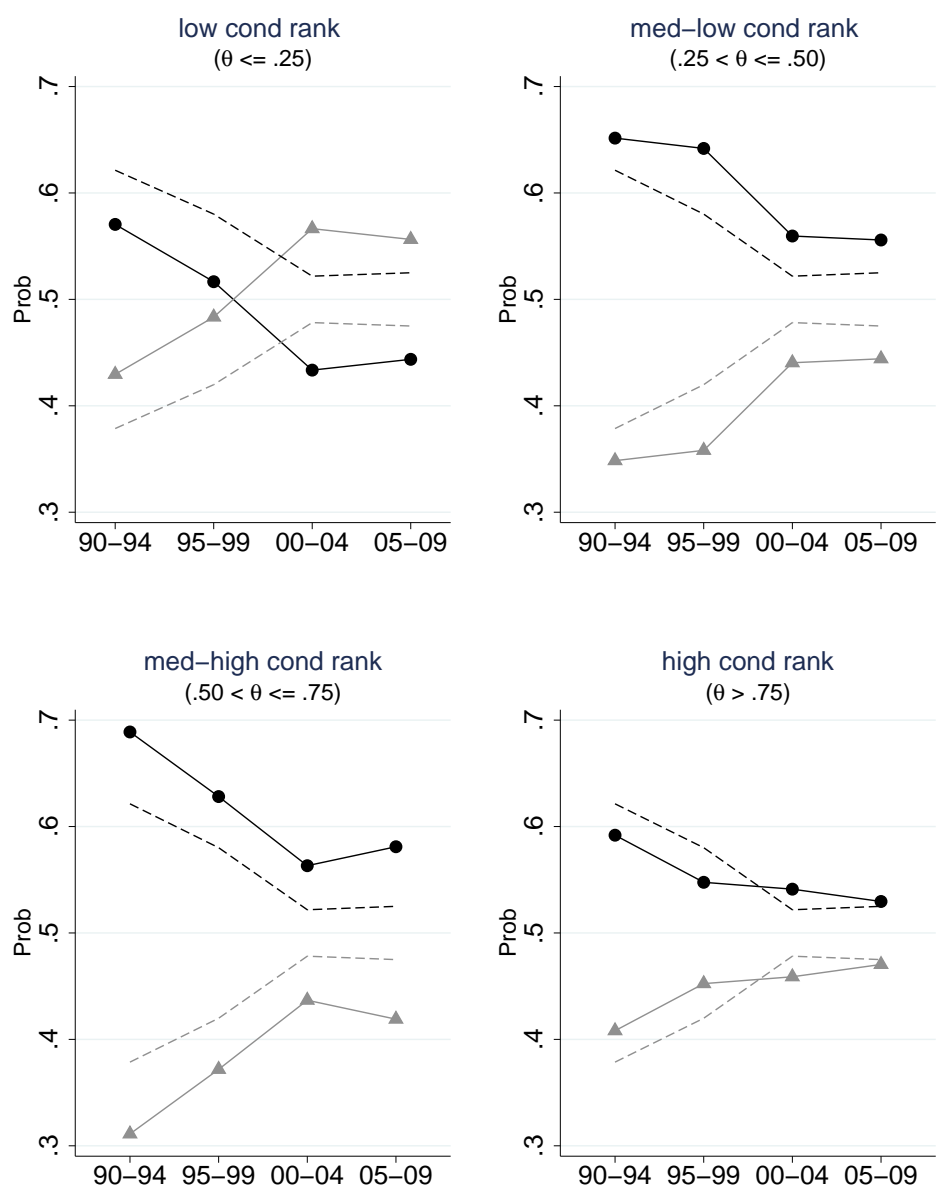

Source: SOEP.v33, own calculations.

\subsection{Underlying Mechanisms}

In the following I discuss two potential mechanisms behind the results on the part-time wage gap: job-skills mismatch and the distribution of job tasks in full- and part-time employment.

\subsubsection{Job-Skills Mismatch}

The existence of a persistent corrected part-time wage penalty at the bottom of the distribution over time implies that for this part of the distribution returns to human capital are lower in parttime employment than in full-employment. In my framework, the existence of regular occupational segregation - understood as well-paid jobs being offered in full-time basis and worse-paid jobs being offered in part-time basis - will surely contribute toward the widening of the raw part-time wage gap but it needs not contribute to the corrected part-time wage gap if occupational choices sufficiently correlate with the human capital variables included in the wage model. However, if individuals working in part-time carry out occupations that do not match their skills, this may well be a contributing factor for the corrected part-time wage penalty found earlier on. In order to examine this issue, Table 4 uses information contained in the GSOEP as to whether an individual's job corresponds to her previous training and reports the share of job-skills mismatches in full- and 
part-time employment by quartiles of each wage distribution.

Table 4: Mismatch between current job and previous training, by wage quartiles

\begin{tabular}{lccccccc}
\hline & \multicolumn{3}{c}{$1990 \mathrm{~s}$} & & \multicolumn{3}{c}{$2000 \mathrm{~s}$} \\
\cline { 2 - 4 } \cline { 6 - 8 } Wage quartiles & FT & PT & Difference & & FT & PT & Difference \\
\hline $1^{\text {st }}$ & .30 & .51 & $-.21^{*}$ & & .33 & .56 & $-.23^{*}$ \\
$2^{\text {nd }}$ & .33 & .43 & $-.10^{*}$ & & .27 & .45 & $-.17^{*}$ \\
$3^{r d}$ & .28 & .32 & $-.04^{*}$ & & .23 & .35 & $-.12^{*}$ \\
$4^{\text {th }}$ & .25 & .23 & $.02^{*}$ & & .21 & .24 & $-.03^{*}$ \\
\hline
\end{tabular}

Source: SOEP.v33, own calculations. Weighting factors used. ${ }^{*}$ significance at $95 \%$ level

Notes: Results based on SOEP variable pgerljob. Units are proportions of each cell (i.e. in the 1990 s, $51 \%$ of all part-time employees with a wage below the P25 in the part-time wage distribution are not doing a job that corresponds to their training.)

Table 4 reveals that job inadequacy at the lowest quartile of the wage distribution is more than 20 percent points higher in part-time than in full-time employment throughout the twenty years under study. While every second part-time employee with a wage in the lower quartile of the parttime distribution was carrying out a job that did not correspond to her training, this was only the case for every third employee in full-time employment. Across the wage distribution, the mismatch gap between full- and part-time employment decreases quickly while, over time, differences in the prevalence of job-skills mismatch between full- and part-time employment increase.

Figure 11: Job Mismatch and Wages
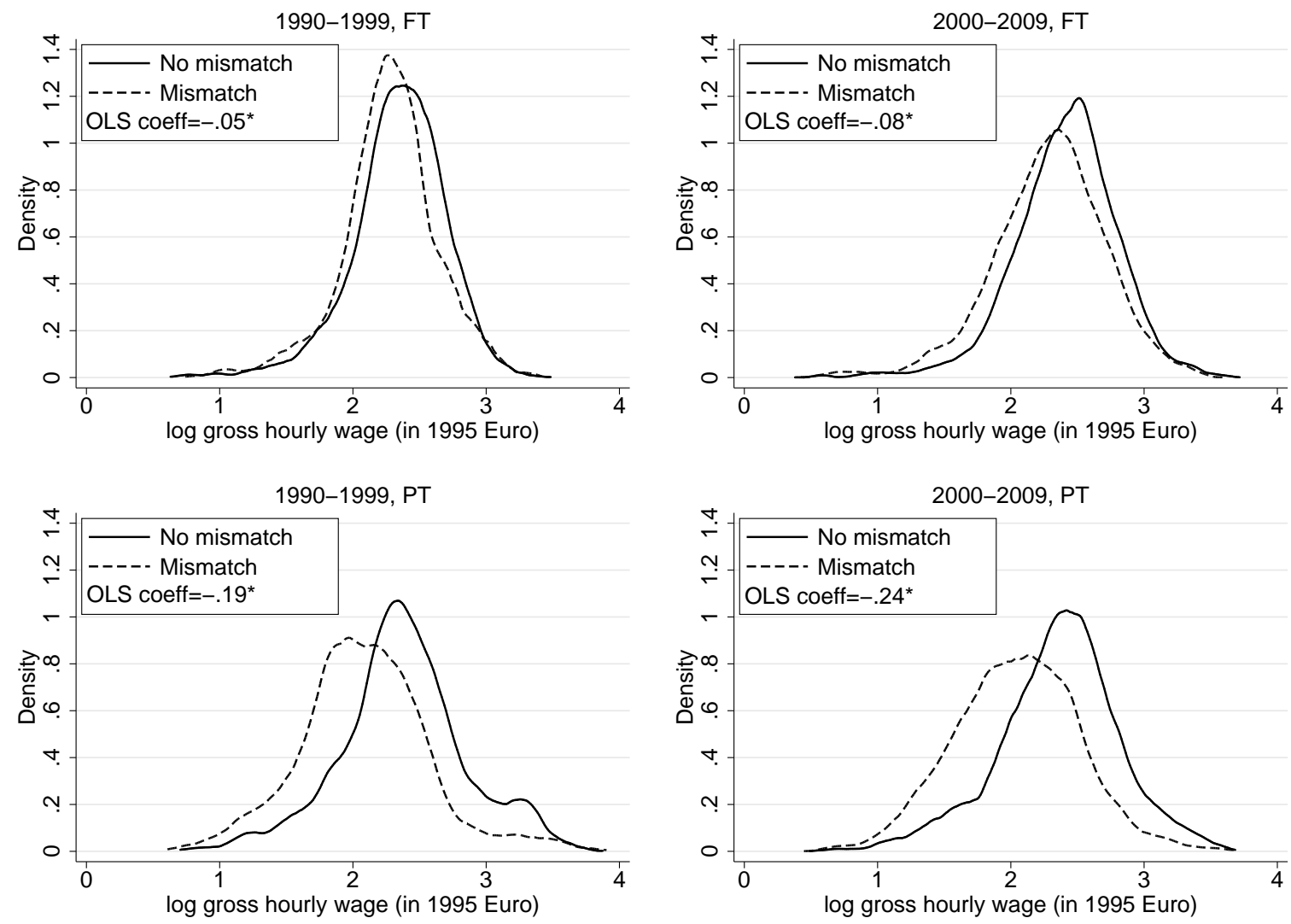

Source: SOEP v.33, own calculations. * stands for statistical significance at the $99 \%$ level. 
However, job-skills mismatches could be in principle both positively and negatively associated with wages. Figure 11 depicts the wage distributions of those who report a mismatch and compares them to the wage distributions of those who report doing a job that corresponds to their previous training. In addition, Figure 11 also reports the OLS coefficient for the indicator variable mismatch, which results from regressing log wages on the set of human capital variables included in the wage model, the mismatch indicator, as well as a set of year indicators. Both the graphs and the regression coefficients show that job missmatch is associated with lower wages both in full- and in part-time employment, although the association is much stronger in part-time employment.

Table 5 shows the prevalence of job-skills mismatch by selected characteristics. In terms of educational achievement, Table 5 reveals that the job-skills mismatch is most prevalent among women with no or low educational degree - both in full- and part-time employment. In both employment kinds, the mismatch decreases with higher educational achievement. However, over time the job-skills mismatch has risen most steeply for part-time working women with an advanced degree, going from 22 per cent in the 1990s up to 33 per cent in the 2000s. Further, the probability of job-skills mismatch also rises substantially with the length of non-market work phases. Within part-time employment, most job mismatches occur in short-hours jobs.

Table 5: Job mismatch, by selected characteristics

\begin{tabular}{|c|c|c|c|c|}
\hline & FT-1990s & PT-1990s & FT-2000s & PT-2000s \\
\hline \multicolumn{5}{|l|}{ by educational achievement } \\
\hline no/low degree & .47 & .56 & .45 & .61 \\
\hline medium degree & .26 & .34 & .25 & .40 \\
\hline advanced degree & .17 & .22 & .18 & .33 \\
\hline \multicolumn{5}{|c|}{ by years of full-time working experience } \\
\hline up to 5 years & .25 & .48 & .21 & .53 \\
\hline $5+$ up to 10 years & .33 & .39 & .26 & .40 \\
\hline more than 10 years & .38 & .40 & .34 & .45 \\
\hline \multicolumn{5}{|c|}{ by years of part-time working experience } \\
\hline up to 5 years & .23 & .55 & .19 & .54 \\
\hline $5+$ up to 10 years & .43 & .43 & .31 & .47 \\
\hline more than 10 years & .50 & .41 & .38 & .45 \\
\hline \multicolumn{5}{|l|}{ by years of non-market work } \\
\hline up to 3 years & .29 & .34 & .23 & .36 \\
\hline $3+$ up to 6 years & .31 & .40 & .31 & .36 \\
\hline more than 6 years & .45 & .49 & .41 & .56 \\
\hline \multicolumn{5}{|c|}{ by short- vs long- part-time employment } \\
\hline short (up to 15 hours/week) & - & .61 & - & .63 \\
\hline long (more than 15 hours/week) & - & .37 & - & .39 \\
\hline \multicolumn{5}{|c|}{ Source: SOEP.v33, own calculations. Weighting factors used. } \\
\hline \multicolumn{5}{|c|}{$\begin{array}{l}\text { Notes: This table includes only individuals who report either having a job that matches their training or } \\
\text { having a job that does not match their training. Individuals who report having no training at all as well } \\
\text { as those currently in training are not included. }\end{array}$} \\
\hline
\end{tabular}

\subsubsection{Full- and Part-Time Jobs: Unequal Distribution of Tasks}

Now I turn to examining the kind of tasks undertaken in full- and part-time employment. To this end, I follow an approach similar to that of Acemoglu and Autor (2011) and, in particular, the operationalisation suggested by Cavaglia and Etheridge (2017) for Germany, and classify occupa- 
tions according to the nature of their main task into four categories: non-routine cognitive, routine cognitive, non-routine manual, and routine manual. ${ }^{20}$. The resulting distribution of main tasks are shown in Figure 12, separately by full- and part-time employment and by decade.

Figure 12: Distribution of main tasks by full- and part-time employment status

(a) wage $\leq \mathrm{P} 25$

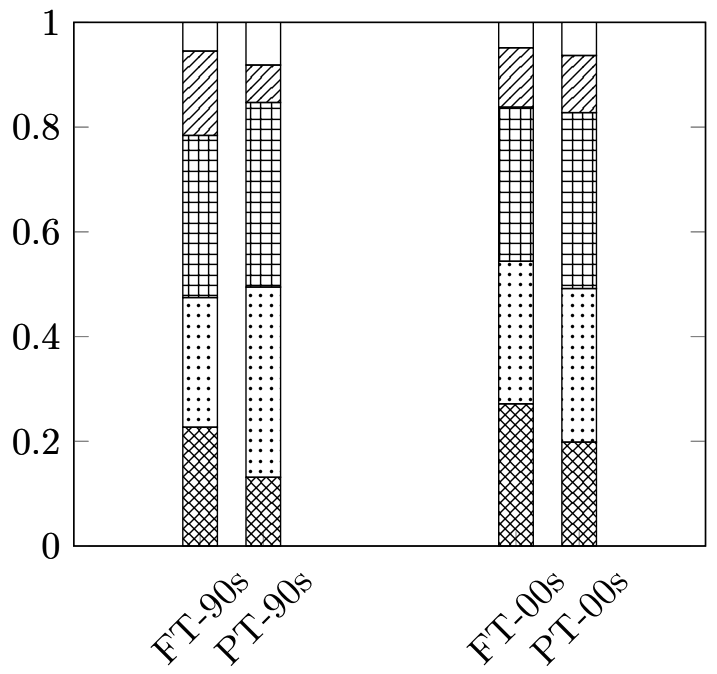

(c) $\mathrm{P} 50>$ wage $\leq \mathrm{P} 75$

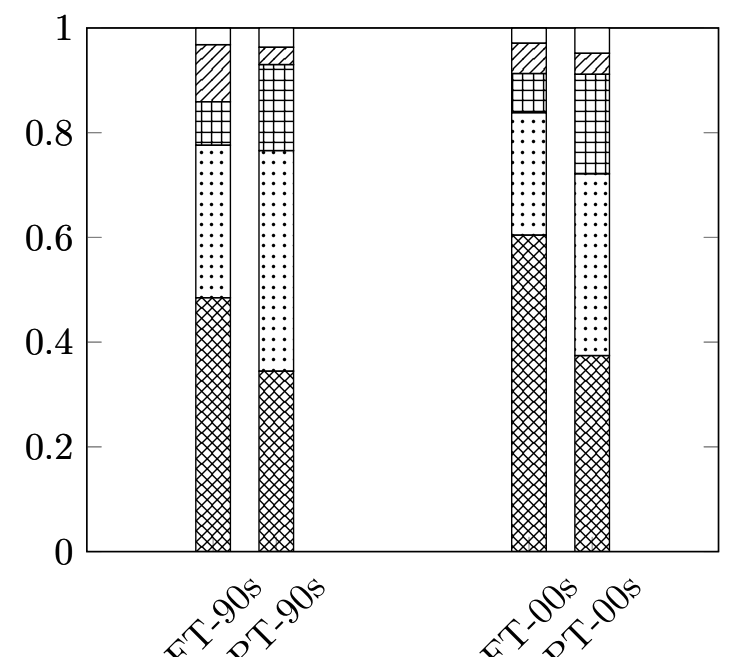

(b) P25> wage $\leq$ P50

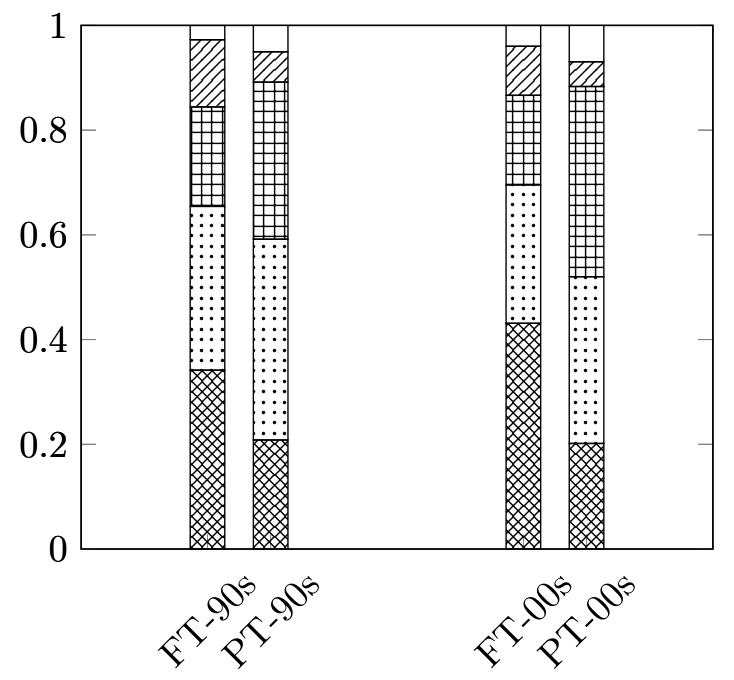

(d) wage $>$ P75

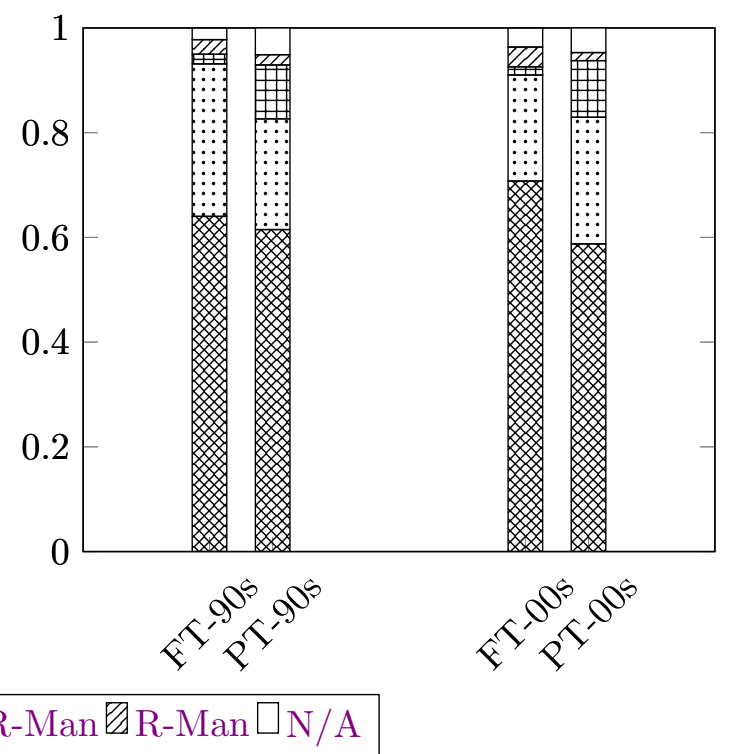

Source: SOEP v.33, own calculations Notes: FT-90s stands for full-time employment in the 19901999 period; PT-90s stands for part-time employment in the 1990-1999 period: FT-00s stands for full-time employment in the 2000-2009 period; PT-00s stands for part-time employment in the 2000-2009 period.

As expected, the share of jobs in occupations whose main task is of non-routine cognitive nature increases across the wage distribution. However, I find the rise in non-routine cognitive tasks over time - pointed to be a cause for women's rising relative full-time wages (Spitz-Oener 2006 and Black and Spitz-Oener 2010) - to occur almost exclusively in full-time employment. This is most evident for the second and third wage quartiles, where non-routine cognitive full-time jobs increased by 9

${ }^{20}$ The categorization is based on ISCO88 occupational codes available in the GSOEP. 
to 12 percentage points over the 1990-2009 period, while the percentage of equivalent part-time jobs stayed constant. To a lesser extent, the same diverging trend is observed for the fourth wage quartile, where the distribution of main tasks among the two sectors was very similar during the 1990s but during the 2000s substantial differences in the share of non-routine cognitive tasks became evident. On the contrary, in the first wage quartile - where the raw part-time wage gap is the highest -, the distribution of main tasks is increasingly similar over time. The diverging development of non-routine, cognitive tasks in full- and part-time employment over time is consistent with the fast rise in job-skills mismatch among part-time employees with an advanced educational degree. This poses the question whether the evolution of job tasks in full- and part-time employment shown in Figure 12 is driven by developments in terms of labor supply or demand. If job sharing of non-routine cognitive tasks is associated with higher (financial, organizational) costs, the demand for highly skilled personnel on a part-time basis may have decreased. Alternatively, from the labor supply perspective, highly educated women may have stronger preferences towards full-time employment - eventually reinforced by rising wage inequality and increasing returns to skill (cf. Mulligan and Rubinstein, 2008). Regardless of the driving force behind the rising differences in terms of tasks, Figure 12 suggests increasing job segregation among the two kinds of employment, which corroborates the findings in terms of selection into full- and part-time employment.

\section{Conclusion}

This paper studies the part-time wage gap in West Germany for the years 1990 to 2009, a time period in which part-time employment expanded dramatically and the average raw part-time wage penalty almost doubled. Next to exploring the part-time wage gap, the paper also offers some insights into the evolution of female part-time wages throughout this time period, for which little is known as compared to full-time wages (Dustmann et al., 2009, Biewen et al., 2018, among others). From the methodological perspective, the paper uses a novel econometric model that allows to study the part-time wage gap across the wage distribution, while controlling for selection into full- and part-time employment. The selection correction assumes the time invariance of the unobservables conditional on the observables (see Melly and Santangelo 2014, 2015) in order to impute non-realized, counterfactual full- and part-time wages.

My findings reveal a large variation of the raw part-time wage gap across the distribution and over time. The corrected part-time wage gap is much lowest than the raw gap and also decreases along the wage distribution. Importantly, I find a persistent corrected part-time penalty at the lower quartile of the distribution throughout the twenty years under study. The widening of the raw part-time wage gap over time is mostly the result of opposite selection patterns into fulland part-time employment. While selection into full-time employment is found to be increasingly positive over time, selection into part-time employment goes from being positive at the beginning of the 1990s to vanishing by the end of the 2000s, even turning negative at the lower end of the distribution. An exploration of potential underlying mechanisms reveals a large share of job-skills mismatch as well as rising differences in the tasks carried out in full- and part-time employment.

Importantly, a zero corrected part-time wage gap is fully compatible with the finding in the literature that returns to part-time working experience are lower than those to full-time working experience (see Blundell et al. (2016) for the UK). In fact, the paper shows that selection in both 
observable and unobservable characteristics increasingly explain the widening of the raw part-time wage gap over time. Although the contribution of each relevant characteristic is not quantified in the paper, the data shows that differences in actual full- and part-time working experience among women engaging in one or the other kind of employment are large. This finding suggests that different returns to actual full- and part-time working experience may be a major factor behind the raw part-time wage gap. Therefore, from the policy perspective it would be meaningful to explore ways of reducing the difficulties attached to transitioning between full- and part-time employment (in both directions) as well as removing constraints that hinder women who wish to engage in full-time employment from doing so. Constraints may be very different in nature, such as inadequate full-time childcare arrangements or disincentives in the tax system - especially for second earners in joint taxation regimes. Further, in the light of the increasing differences in job tasks between full- and part-time employment, new models of job sharing could be explored with the goal of making as many jobs as possible available in both full- and part-time basis. Finally, given the large share of job-skills mismatch in part-time employment at the lower half of the distribution, priority should be placed in policies of lifelong learning directed towards enabling individuals with low education and/or long non-market employment spells to carry out a job that fits their skills. 


\section{References}

Aaronson, D. and French, E., 2004. The effect of part-time work on wages: Evidence from the social security rules. Journal of Labor Economics, 22(2):329-352.

Acemoglu, D. and Autor, D., 2011. Skills, Tasks and Technologies: Implications for Employment and Earnings, volume 4 of Handbook of Labor Economics, chapter 12, pages 1043-1171. Elsevier.

Arellano, M. and Bonhomme, S., 2017. Quantile selection models with an application to understanding changes in wage inequality. Econometrica, 85(1):1-28.

Athey, S. and Imbens, G. W., 2006. Identification and inference in nonlinear difference-indifferences models. Econometrica, 74(2):431-497.

Averett, S. L. and Hotchkiss, J. L., 1996. Discrimination in the payment of full-time wage premiums. Industrial and Labor Relations Review, 49(2):287-301.

Bardasi, E. and Gornick, J. C., 2008. Working for less? Women's part-time wage penalties across countries. Feminist Economics, 14(1):37-72.

Biewen, M., Fitzenberger, B., and de Lazzer, J., 2018. The role of employment interruptions and part-time work for the rise in wage inequality. IZA Journal of Labor Economics, forthcoming.

Black, S. E. and Spitz-Oener, A., 2010. Explaining women's success: Technological change and the skill content of women's work. Review of Economics and Statistics, 92(1):187-194.

Blank, R. M., 1990. Are part-time jobs lousy jobs. In A Future of Lousy Jobs? The Brookings Institute, Washington DC.

Blau, F. D. and Kahn, L. M., 2006. The U.S. gender pay gap in the 1990s: Slowing convergence. Industrial and Labor Relations Review, 60(1):45-66.

2017. The gender wage gap: Extent, trends, and explanations. Journal of Economic Literature, 55(3):789-865.

Blinder, A. S., 1973. Wage discrimination: Reduced form and structural estimates. The Journal of Human Resources, 8(4):pp. 436-455.

Blundell, R., Costa Dias, M., Meghir, C., and Shaw, J., 2016. Female labor supply, human capital, and welfare reform. Econometrica, 84(5):1705-1753.

Blundell, R., Gosling, A., Ichimura, H., and Meghir, C., 2007. Changes in the distribution of male and female wages accounting for employment composition using bounds. Econometrica, $75(2): 323-363$.

Booth, A. L. and Wood, M., 2008. Back-to-front down under? Part-time/full-time wage differentials in Australia. Industrial Relations: A Journal of Economy and Society, 47(1):114-135.

Bowlus, A. J. and Grogan, L., 2009. Gender wage differentials, job search, and part-time employment in the UK. Oxford Economic Papers, 61(2):275-303. 
Carrillo-Tudela, C., Launov, A., and Robin, J.-M., 2018. The fall in German unemployment: A flow analysis. Working Paper.

Cavaglia, C. and Etheridge, B., 2017. Job polarisation and the declining quality of knowledge workers: Evidence from the UK and Germany. ISER Working Paper Series 2017-09.

Chernozhukov, V., FernándezVal, I., and Melly, B., 2013. Inference on counterfactual distributions. Econometrica, 81(6):2205-2268.

Chernozhukov, V. and Hansen, C., 2005. An IV model of quantile treatment effects. Econometrica, $73(1): 245-261$.

Connolly, S. and Gregory, M., 2009. The part-time pay penalty: earnings trajectories of British women. Oxford Economic Papers, 61(suppl 1):i76-i97.

— 2010. Dual tracks: part-time work in life-cycle employment for British women. Journal of Population Economics, 23(3):907-931.

DiNardo, J., Fortin, N. M., and Lemieux, T., 1996. Labor market institutions and the distribution of wages, 1973-1992: A semiparametric approach. Econometrica, 64(5):1001-1044.

Dustmann, C., Ludsteck, J., and Schönberg, U., 2009. Revisiting the German wage structure. The Quarterly Journal of Economics, 124(2):843-881.

Ermisch, J. F. and Wright, R. E., 1993. Wage offers and full-time and part-time employment by British women. The Journal of Human Resources, 28(1):111-133.

Fernández-Kranz, D. and Rodriguez-Planas, N., 2011. The part-time pay penalty in a segmented labor market. Labour Economics, 18(5):591-606.

Fouarge, D. and Muffels, R., 2009. Working Part-Time in The British, German and Dutch Labour Market: Scarring for the Wage Career? Schmollers Jahrbuch : Journal of Applied Social Science Studies / Zeitschrift f?r Wirtschafts- und Sozialwissenschaften, 129(2):217-226.

Goldin, C., 2014. A grand gender convergence: Its last chapter. American Economic Review, 104(4):1091-1119.

Gronau, R., 1974. Wage comparisons-a selectivity bias. Journal of Political Economy, 82(6):111943.

Heckman, J. J., 1979. Sample selection bias as a specification error. Econometrica, 47(1):pp. $153-161$.

Hirsch, B. T., 2005. Why do part-time workers earn less? The role of worker and job skills. Industrial and Labor Relations Review, 58(4):525-551.

Koenker, R. and Bassett, G. J., 1978. Regression quantiles. Econometrica, 46(1):33-50.

Machado, J. A. F. and Mata, J., 2005. Counterfactual decomposition of changes in wage distributions using quantile regression. Journal of Applied Econometrics, 20(4):445-465. 
Manning, A. and Petrongolo, B., 2008. The part-time pay penalty for women in Britain. The Economic Journal, 118(526):F28-F51.

Matteazzi, E., Pailhé, A., and Solaz, A., 2014. Part-time wage penalties for women in prime age. Industrial and Labor Relations Review, 67(3):955-985.

Melly, B. and Santangelo, G., 2014. The evolution of the gender wage gap: 1968-2008. Working Paper.

, 2015. The changes-in-changes model with covariates. Working Paper.

Mocan, H. N. and Tekin, E., 2003. Nonprofit sector and part-time work: An analysis of employeremployee matched data on child care workers. The Review of Economics and Statistics, 85(1):3850.

Mulligan, C. B. and Rubinstein, Y., 2008. Selection, investment, and women's relative wages over time. The Quarterly Journal of Economics, 123(3):1061-1110.

Mumford, K. and Smith, P. N., 2009. What determines the part-time and gender earnings gaps in Britain: Evidence from the workplace. Oxford Economic Papers, 61:i56-i75.

Neal, D., 2004. The measured black-white wage gap among women is too small. Journal of Political Economy, 112(S1):S1-S28.

Oaxaca, R., 1973. Male-female wage differentials in urban labor markets. International Economic Review, 14(3):693-709.

OECD, 2010. Employment Outlook 2010, chapter How Good is Part-Time Work?, pages 211-266. OECD Publishing, Paris.

- 2016. Employment outlook 2016. Technical report, Organisation for Economic Cooperation and Development.

Olivetti, C. and Petrongolo, B., 2008. Unequal pay or unequal employment? A cross country analysis of gender gaps. Journal of Labor Economics, 26(4):621-654.

Paul, M., 2016. Is there a causal effect of working part-time on current and future wages? The Scandinavian Journal of Economics, 118(3):494-523.

Roy, A., 1951. Some thoughts on the distribution of earnings. Oxford Economic Papers, 3(2):135146.

Spitz-Oener, A., 2006. Technical change, job tasks, and rising educational demands: Looking outside the wage structure. Journal of Labor Economics, 24(2):235-270.

Wagner, G. G., Frick, J. R., and Schupp, J., 2007. The German Socio-Economic Panel Study (SOEP): Scope, evolution and enhancements. Schmollers Jahrbuch, 127(1):139-170.

Wolf, E., 2002. Lower wage rates for fewer hours? a simultaneous wage-hours model for germany. Labour Economics, 9(5):643 - 663. 


\section{A. Tables}

Table A1: Person-Year Observations, Full-Time Status

\begin{tabular}{|c|c|c|c|c|c|c|c|}
\hline & \multirow{2}{*}{$\begin{array}{l}\text { All } \\
(1) \\
\end{array}$} & \multirow{2}{*}{$\frac{\text { Work FT }}{(2)}$} & \multirow{2}{*}{$\frac{\text { Do Not Work FT }}{(3)}$} & \multicolumn{2}{|c|}{ Ever Worked FT } & \multicolumn{2}{|c|}{ Never Worked FT } \\
\hline & & & & $(4)$ & $\%$ of $(3)$ & $(5)$ & $\%$ of $(1)$ \\
\hline 1984 & 3201 & 972 & 2229 & 713 & $32 \%$ & 1516 & $47 \%$ \\
\hline 1985 & 3295 & 1050 & 2245 & 722 & $32 \%$ & 1523 & $46 \%$ \\
\hline 1986 & 3177 & 1034 & 2143 & 746 & $35 \%$ & 1397 & $44 \%$ \\
\hline 1987 & 3112 & 1040 & 2072 & 781 & $38 \%$ & 1291 & $41 \%$ \\
\hline 1988 & 2963 & 980 & 1983 & 803 & $40 \%$ & 1180 & $40 \%$ \\
\hline 1989 & 2885 & 1041 & 1844 & 756 & $41 \%$ & 1088 & $38 \%$ \\
\hline 1990 & 2847 & 1039 & 1808 & 792 & $44 \%$ & 1016 & $36 \%$ \\
\hline 1991 & 2842 & 1030 & 1812 & 830 & $46 \%$ & 982 & $35 \%$ \\
\hline 1992 & 2825 & 998 & 1827 & 899 & $49 \%$ & 928 & $33 \%$ \\
\hline 1993 & 2798 & 1009 & 1789 & 896 & $50 \%$ & 893 & $32 \%$ \\
\hline 1994 & 2745 & 933 & 1812 & 943 & $52 \%$ & 869 & $32 \%$ \\
\hline 1995 & 2907 & 982 & 1925 & 1020 & $53 \%$ & 905 & $31 \%$ \\
\hline 1996 & 2845 & 953 & 1892 & 1035 & $55 \%$ & 857 & $30 \%$ \\
\hline 1997 & 2766 & 932 & 1834 & 1031 & $56 \%$ & 803 & $29 \%$ \\
\hline 1998 & 2961 & 970 & 1991 & 1086 & $55 \%$ & 905 & $31 \%$ \\
\hline 1999 & 2846 & 987 & 1859 & 1030 & $55 \%$ & 829 & $29 \%$ \\
\hline 2000 & 4632 & 1527 & 3105 & 1357 & $44 \%$ & 1748 & $38 \%$ \\
\hline 2001 & 4524 & 1474 & 3050 & 1348 & $44 \%$ & 1702 & $38 \%$ \\
\hline 2002 & 4737 & 1536 & 3201 & 1489 & $47 \%$ & 1712 & $36 \%$ \\
\hline 2003 & 4590 & 1515 & 3075 & 1464 & $48 \%$ & 1611 & $35 \%$ \\
\hline 2004 & 4371 & 1412 & 2959 & 1476 & $50 \%$ & 1483 & $34 \%$ \\
\hline 2005 & 4125 & 1358 & 2767 & 1422 & $51 \%$ & 1345 & $33 \%$ \\
\hline 2006 & 4236 & 1404 & 2832 & 1436 & $51 \%$ & 1396 & $33 \%$ \\
\hline 2007 & 3985 & 1345 & 2640 & 1359 & $51 \%$ & 1281 & $32 \%$ \\
\hline 2008 & 3677 & 1284 & 2393 & 1252 & $52 \%$ & 1141 & $31 \%$ \\
\hline 2009 & 3338 & 1208 & 2130 & 1154 & $54 \%$ & 976 & $29 \%$ \\
\hline 2010 & 5574 & 1352 & 4222 & 1616 & $38 \%$ & 2606 & $47 \%$ \\
\hline 2011 & 6507 & 1742 & 4765 & 1601 & $34 \%$ & 3164 & $49 \%$ \\
\hline 2012 & 6323 & 1809 & 4514 & 1480 & $33 \%$ & 3034 & $48 \%$ \\
\hline 2013 & 7171 & 2034 & 5137 & 1566 & $30 \%$ & 3571 & $50 \%$ \\
\hline 2014 & 6615 & 1996 & 4619 & 1391 & $30 \%$ & 3228 & $49 \%$ \\
\hline 2015 & 6402 & 1932 & 4470 & 1262 & $28 \%$ & 3208 & $50 \%$ \\
\hline 2016 & 5663 & 1849 & 3814 & 1013 & $27 \%$ & 2801 & $49 \%$ \\
\hline
\end{tabular}

Source: SOEP.v33, own calculations. 
Table A2: Person-Year Observations, Part-Time Status

\begin{tabular}{|c|c|c|c|c|c|c|c|}
\hline & \multirow{2}{*}{$\begin{array}{l}\text { All } \\
(1) \\
\end{array}$} & \multirow{2}{*}{$\begin{array}{c}\text { Work PT } \\
(2) \\
\end{array}$} & \multirow{2}{*}{$\frac{\text { Do Not Work PT }}{(3)}$} & \multicolumn{2}{|c|}{ Ever Worked PT } & \multicolumn{2}{|c|}{ Never Worked PT } \\
\hline & & & & (4) & $\%$ of $(3)$ & $(5)$ & $\%$ of $(1)$ \\
\hline 1984 & 3201 & 517 & 2684 & 1053 & $39 \%$ & 1631 & $51 \%$ \\
\hline 1985 & 3295 & 559 & 2736 & 1063 & $39 \%$ & 1673 & $51 \%$ \\
\hline 1986 & 3177 & 534 & 2643 & 1093 & $41 \%$ & 1550 & $49 \%$ \\
\hline 1987 & 3112 & 542 & 2570 & 1112 & $43 \%$ & 1458 & $47 \%$ \\
\hline 1988 & 2963 & 548 & 2415 & 1089 & $45 \%$ & 1326 & $45 \%$ \\
\hline 1989 & 2885 & 516 & 2369 & 1136 & $48 \%$ & 1233 & $43 \%$ \\
\hline 1990 & 2847 & 543 & 2304 & 1128 & $49 \%$ & 1176 & $41 \%$ \\
\hline 1991 & 2842 & 600 & 2242 & 1100 & $49 \%$ & 1142 & $40 \%$ \\
\hline 1992 & 2825 & 577 & 2248 & 1143 & $51 \%$ & 1105 & $39 \%$ \\
\hline 1993 & 2798 & 565 & 2233 & 1156 & $52 \%$ & 1077 & $38 \%$ \\
\hline 1994 & 2745 & 575 & 2170 & 1124 & $52 \%$ & 1046 & $38 \%$ \\
\hline 1995 & 2907 & 645 & 2262 & 1161 & $51 \%$ & 1101 & $38 \%$ \\
\hline 1996 & 2845 & 655 & 2190 & 1125 & $51 \%$ & 1065 & $37 \%$ \\
\hline 1997 & 2766 & 634 & 2132 & 1115 & $52 \%$ & 1017 & $37 \%$ \\
\hline 1998 & 2961 & 677 & 2284 & 1229 & $54 \%$ & 1055 & $36 \%$ \\
\hline 1999 & 2846 & 749 & 2097 & 1109 & $53 \%$ & 988 & $35 \%$ \\
\hline 2000 & 4632 & 1352 & 3280 & 1634 & $50 \%$ & 1646 & $36 \%$ \\
\hline 2001 & 4524 & 1387 & 3137 & 1537 & $49 \%$ & 1600 & $35 \%$ \\
\hline 2002 & 4737 & 1512 & 3225 & 1587 & $49 \%$ & 1638 & $35 \%$ \\
\hline 2003 & 4590 & 1508 & 3082 & 1507 & $49 \%$ & 1575 & $34 \%$ \\
\hline 2004 & 4371 & 1451 & 2920 & 1465 & $50 \%$ & 1455 & $33 \%$ \\
\hline 2005 & 4125 & 1393 & 2732 & 1408 & $52 \%$ & 1324 & $32 \%$ \\
\hline 2006 & 4236 & 1429 & 2807 & 1448 & $52 \%$ & 1359 & $32 \%$ \\
\hline 2007 & 3985 & 1401 & 2584 & 1340 & $52 \%$ & 1244 & $31 \%$ \\
\hline 2008 & 3677 & 1308 & 2369 & 1220 & $51 \%$ & 1149 & $31 \%$ \\
\hline 2009 & 3338 & 1188 & 2150 & 1140 & $53 \%$ & 1010 & $30 \%$ \\
\hline 2010 & 5574 & 1925 & 3649 & 1939 & $53 \%$ & 1710 & $31 \%$ \\
\hline 2011 & 6507 & 2518 & 3989 & 1904 & $48 \%$ & 2085 & $32 \%$ \\
\hline 2012 & 6323 & 2478 & 3845 & 1776 & $46 \%$ & 2069 & $33 \%$ \\
\hline 2013 & 7171 & 2843 & 4328 & 1835 & $42 \%$ & 2493 & $35 \%$ \\
\hline 2014 & 6615 & 2664 & 3951 & 1667 & $42 \%$ & 2284 & $35 \%$ \\
\hline 2015 & 6402 & 2509 & 3893 & 1530 & $39 \%$ & 2363 & $37 \%$ \\
\hline 2016 & 5663 & 2283 & 3380 & 1309 & $39 \%$ & 2071 & $37 \%$ \\
\hline
\end{tabular}

Source: SOEP.v33, own calculations. 
Table A3: Availability of multiple imputations

\begin{tabular}{|c|c|c|c|c|c|c|c|}
\hline & \multirow{2}{*}{$\begin{array}{l}\text { All } \\
(1)\end{array}$} & \multirow{2}{*}{$\frac{\text { Need FT Imp }}{(2)}$} & \multicolumn{2}{|c|}{ Multiple FT avail. } & \multirow{2}{*}{$\frac{\text { Need PT Imp }}{(4)}$} & \multicolumn{2}{|c|}{ Multiple PT avail } \\
\hline & & & (3) & $\%$ of $(2)$ & & $(5)$ & $\%$ of $(4)$ \\
\hline 1990 & 2847 & 1808 & 630 & $35 \%$ & 2304 & 871 & $38 \%$ \\
\hline 1991 & 2842 & 1812 & 663 & $37 \%$ & 2242 & 845 & $38 \%$ \\
\hline 1992 & 2825 & 1827 & 727 & $40 \%$ & 2248 & 889 & $40 \%$ \\
\hline 1993 & 2798 & 1789 & 726 & $41 \%$ & 2233 & 900 & $40 \%$ \\
\hline 1994 & 2745 & 1812 & 769 & $42 \%$ & 2170 & 894 & $41 \%$ \\
\hline 1995 & 2907 & 1925 & 821 & $43 \%$ & 2262 & 919 & $41 \%$ \\
\hline 1996 & 2845 & 1892 & 825 & $44 \%$ & 2190 & 884 & $40 \%$ \\
\hline 1997 & 2766 & 1834 & 834 & $45 \%$ & 2132 & 885 & $42 \%$ \\
\hline 1998 & 2961 & 1991 & 873 & $44 \%$ & 2284 & 975 & $43 \%$ \\
\hline 1999 & 2846 & 1859 & 821 & $44 \%$ & 2097 & 865 & $41 \%$ \\
\hline 2000 & 4632 & 3105 & 1072 & $35 \%$ & 3280 & 1255 & $38 \%$ \\
\hline 2001 & 4524 & 3050 & 1032 & $34 \%$ & 3137 & 1175 & $37 \%$ \\
\hline 2002 & 4737 & 3201 & 1159 & $36 \%$ & 3225 & 1204 & $37 \%$ \\
\hline 2003 & 4590 & 3075 & 1135 & $37 \%$ & 3082 & 1138 & $37 \%$ \\
\hline 2004 & 4371 & 2959 & 1155 & $39 \%$ & 2920 & 1086 & $37 \%$ \\
\hline 2005 & 4125 & 2767 & 1119 & $40 \%$ & 2732 & 1045 & $38 \%$ \\
\hline 2006 & 4236 & 2832 & 1122 & $40 \%$ & 2807 & 1080 & $38 \%$ \\
\hline 2007 & 3985 & 2640 & 1082 & $41 \%$ & 2584 & 987 & $38 \%$ \\
\hline 2008 & 3677 & 2393 & 991 & $41 \%$ & 2369 & 901 & $38 \%$ \\
\hline 2009 & 3338 & 2130 & 903 & $42 \%$ & 2150 & 829 & $39 \%$ \\
\hline
\end{tabular}

Source: SOEP.v33, own calculations. 
Table A4: Sample Means (Standard Deviations) and Sample Size

\begin{tabular}{|c|c|c|c|c|c|c|c|c|c|c|c|c|c|}
\hline & \multicolumn{2}{|c|}{ age } & \multicolumn{2}{|c|}{$\begin{array}{l}\text { years of } \\
\text { education }\end{array}$} & \multicolumn{2}{|c|}{$\begin{array}{l}\text { intermediate } \\
\text { degree }(0 / 1)\end{array}$} & \multicolumn{2}{|c|}{$\begin{array}{c}\text { advanced } \\
\text { degree }(0 / 1)\end{array}$} & \multicolumn{2}{|c|}{$\begin{array}{l}\text { experience } \\
\text { full-time }\end{array}$} & \multicolumn{2}{|c|}{$\begin{array}{l}\text { experience } \\
\text { part-time }\end{array}$} & \multirow[t]{2}{*}{$\begin{array}{l}\text { sample } \\
\text { size }\end{array}$} \\
\hline \multicolumn{13}{|c|}{ Complete Sample } & \\
\hline 1990-1994 & 36.8 & $(10.2)$ & 11.3 & $(2.3)$ & 0.40 & $(0.49)$ & 0.08 & $(0.27)$ & 8.0 & $(7.6)$ & 2.9 & $(5.1)$ & 14057 \\
\hline 1995-1999 & 37.2 & $(9.7)$ & 11.6 & $(2.5)$ & 0.43 & $(0.50)$ & 0.11 & $(0.31)$ & 8.4 & $(7.8)$ & 3.1 & $(4.9)$ & 14325 \\
\hline 2000-2004 & 37.9 & $(9.6)$ & 11.9 & $(2.4)$ & 0.48 & $(0.50)$ & 0.13 & $(0.34)$ & 8.5 & $(8.0)$ & 3.5 & $(5.5)$ & 22854 \\
\hline 2005-2009 & 38.5 & $(9.7)$ & 12.2 & $(2.5)$ & 0.51 & $(0.50)$ & 0.16 & $(0.36)$ & 8.6 & $(8.3)$ & 4.2 & $(5.6)$ & 19361 \\
\hline \multicolumn{14}{|c|}{ Subsample Working Full-Time } \\
\hline 1990-1994 & 35.1 & $(10.2)$ & 11.5 & $(2.4)$ & 0.45 & $(0.50)$ & 0.09 & $(0.29)$ & 11.4 & (9.0) & 1.6 & (3.7) & 5009 \\
\hline 1995-1999 & 36.4 & $(9.8)$ & 11.9 & $(2.5)$ & 0.45 & $(0.50)$ & 0.14 & $(0.35)$ & 12.3 & $(9.1)$ & 1.6 & $(3.5)$ & 4824 \\
\hline $2000-2004$ & 37.3 & $(9.7)$ & 12.4 & $(2.5)$ & 0.50 & $(0.50)$ & 0.18 & $(0.38)$ & 12.7 & $(9.2)$ & 1.8 & $(3.9)$ & 7464 \\
\hline 2005-2009 & 38.2 & $(9.8)$ & 12.7 & $(2.7)$ & 0.50 & $(0.50)$ & 0.22 & $(0.41)$ & 12.8 & $(9.4)$ & 2.4 & $(4.4)$ & 6599 \\
\hline \multicolumn{14}{|c|}{ Subsample Working Part-Time } \\
\hline 1990-1994 & 40.0 & $(8.7)$ & 11.3 & $(2.4)$ & 0.36 & $(0.48)$ & 0.09 & $(0.29)$ & 6.8 & $(5.6)$ & 7.2 & $(6.7)$ & 2860 \\
\hline 1995-1999 & 40.2 & $(8.4)$ & 11.8 & $(2.5)$ & 0.43 & $(0.50)$ & 0.12 & $(0.33)$ & 7.2 & (6.1) & 7.1 & $(6.0)$ & 3360 \\
\hline 2000-2004 & 40.5 & $(8.2)$ & 11.8 & $(2.3)$ & 0.46 & $(0.50)$ & 0.12 & $(0.32)$ & 7.3 & (6.4) & 7.2 & $(6.4)$ & 7210 \\
\hline 2005-2009 & 40.9 & $(8.5)$ & 12.0 & $(2.3)$ & 0.51 & $(0.50)$ & 0.12 & $(0.33)$ & 7.3 & $(6.6)$ & 7.9 & $(6.2)$ & 6719 \\
\hline \multicolumn{14}{|c|}{ Subsample Out-of-Work } \\
\hline 1990-1994 & 36.6 & $(10.6)$ & 11.0 & $(2.3)$ & 0.37 & $(0.48)$ & 0.06 & $(0.24)$ & 5.7 & $(6.0)$ & 1.8 & $(3.9)$ & 6188 \\
\hline 1995-1999 & 36.0 & (10.0) & 11.2 & $(2.4)$ & 0.42 & $(0.49)$ & 0.08 & $(0.27)$ & 6.0 & $(6.2)$ & 1.9 & (3.8) & 6141 \\
\hline 2000-2004 & 36.1 & $(10.1)$ & 11.5 & $(2.4)$ & 0.48 & $(0.50)$ & 0.10 & $(0.30)$ & 5.6 & (6.3) & 2.0 & $(4.1)$ & 8180 \\
\hline 2005-2009 & 36.3 & $(10.1)$ & 11.7 & $(2.4)$ & 0.51 & $(0.50)$ & 0.12 & $(0.32)$ & 5.4 & $(6.3)$ & 2.4 & $(4.1)$ & 6043 \\
\hline
\end{tabular}

Source: SOEP.v33, weighting factors used, own calculations. 


\section{B. Appendix: Goodness of fit of the conditional wage model}

The imputation of non-realized wages is based on the conditional quantile regression wage model presented in Section 2.3. In order to evaluate the in-sample fit of the specification of the wage quantile regression, Figure B1 contrasts observed log hourly wages (solid lines) with those produced by the conditional wage model (dashed lines) at different points of the unconditional distribution. In order to obtain unconditional wage distributions from the grid of conditional quantile regressions, I use the algorithm provided by Chernozhukov et al. (2013), which yields results equivalent to those suggested by Machado and Mata (2005).

Figure B1: Goodness of fit of the conditional wage model
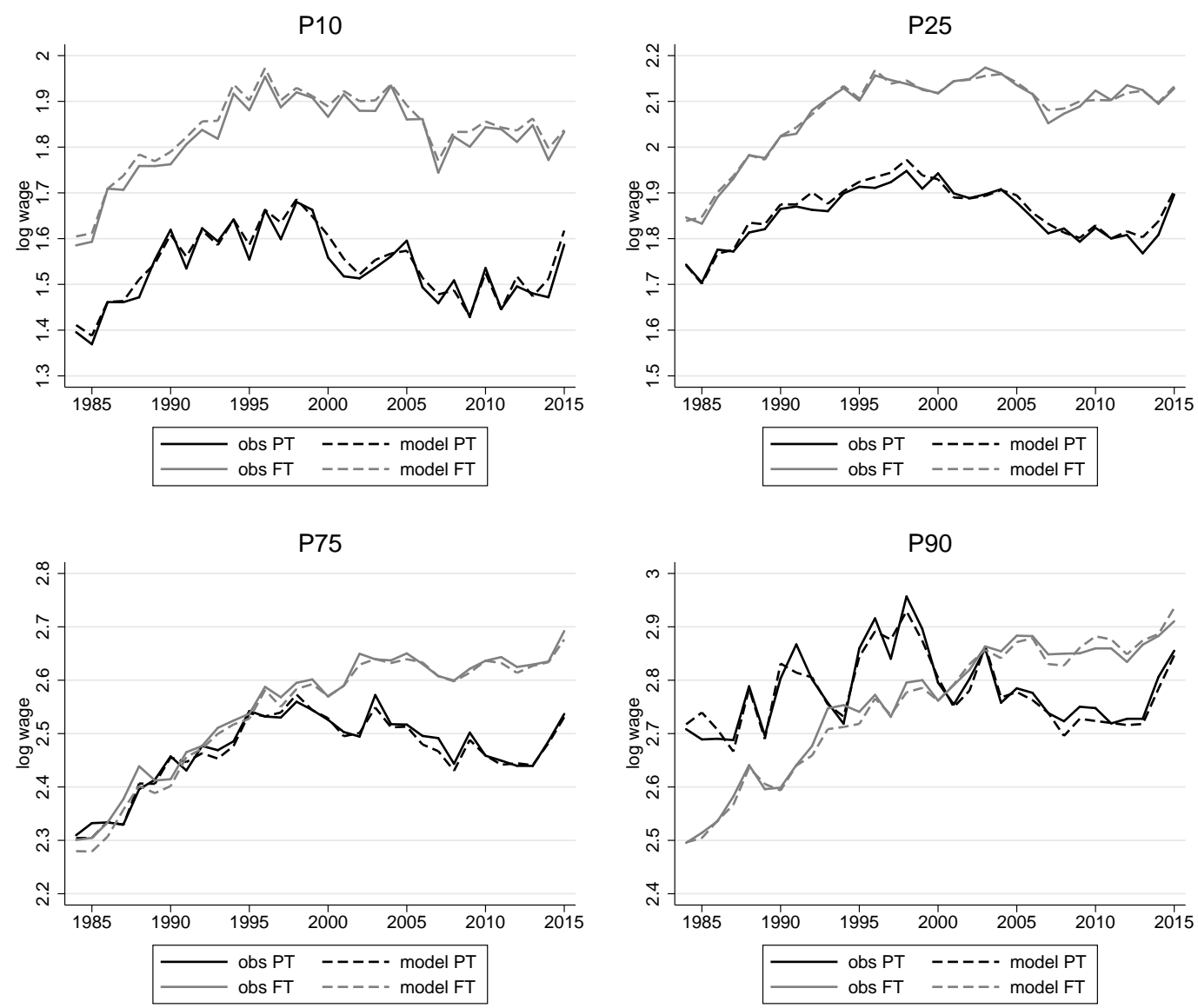

Source: SOEP v.33, own calculations

Figure B1 shows that the conditional wage model fits very well the observed wage data at most points of the distribution, with the exception of a few peaks at the $90^{\text {th }}$ percentile of the part-time distribution for the time period 1995-1999. 


\section{Appendix: Technical Documentation of the Imputation}

Table $\mathrm{C} 1$ tabulates the number of observations for which $g_{k l}^{F T}=1$ by all possible $\{k, l\}$ combinations ( $k$ years in columns, $l$ years in rows). These are observations for whom I impute a full-time wage in year $k$ using information from year $l$. Table $\mathrm{C} 2$ does the equivalent for observations for which $g_{k l}^{P T}=1$.

The imputation of non-realized full- and part-time wages requires estimating 170,280 conditional quantile regressions; the resulting wage equation coefficients are not reported for the sake of brevity. The number of regressions is calculated as the number of all two-year combinations in the data, 430, times the 99 percentiles at which the wage equations are estimated for each two-year combination, times 2 (once for each of the two years), and again times 2 - once for the full- and once for the part-time wage distribution.

Table C3 and C4 display the number of observations for which $g_{k l}^{F T}=0$ and $g_{k l}^{P T}=0$, respectively. These are the subsamples which are the base for the imputation. Quantile regression samples range from 46 to 1,181 observations in the case of full-time work and from 10 to 1,076 observations in the case of part-time work. Around half of all tight grids of quantile regression are estimated on subsamples that have at least 252 observations in the case of the imputations of full-time wages and 164 observations in the case of part-time wages.

For the imputation of part-time wages, I need to establish a cut-off of minimum subsample size. I have set this to 30 observations. This implies that I cannot use the imputation algorithm for 32 out of the 430 possible two-year combinations. This does not affect the results, as for most observations for whom I would be using the information from the dropped two-year combinations there are multiple available imputations. 
Table C1: Full-time wages: Subsample sizes for each grid of quantile regressions

\begin{tabular}{|c|c|c|c|c|c|c|c|c|c|c|c|c|c|c|c|c|c|c|c|c|}
\hline & 1990 & 1991 & 1992 & 1993 & 1994 & 1995 & 1996 & 1997 & 1998 & 1999 & 2000 & 2001 & 2002 & 2003 & 2004 & 2005 & 2006 & 2007 & 2008 & 2009 \\
\hline 1.984 & 242 & 247 & 236 & 239 & 198 & 174 & 166 & 163 & 144 & 149 & 140 & 133 & 114 & 104 & 86 & 80 & 67 & 59 & 51 & 42 \\
\hline 1.985 & 241 & 255 & 233 & 235 & 198 & 170 & 170 & 171 & 152 & 152 & 145 & 131 & 115 & 105 & 84 & 85 & 69 & 57 & 52 & 41 \\
\hline 1.986 & 230 & 249 & 224 & 242 & 203 & 179 & 169 & 172 & 154 & 160 & 150 & 134 & 117 & 111 & 89 & 90 & 81 & 74 & 67 & 52 \\
\hline 1.987 & 236 & 259 & 243 & 245 & 204 & 183 & 172 & 174 & 153 & 154 & 144 & 135 & 116 & 106 & 87 & 91 & 81 & 80 & 69 & 53 \\
\hline 1.988 & 214 & 238 & 226 & 238 & 212 & 193 & 188 & 185 & 168 & 162 & 154 & 143 & 130 & 121 & 99 & 98 & 84 & 86 & 76 & 65 \\
\hline 1.989 & 140 & 190 & 189 & 205 & 183 & 175 & 175 & 171 & 153 & 150 & 155 & 142 & 134 & 121 & 103 & 96 & 87 & 87 & 74 & 60 \\
\hline 1.990 & 0 & 153 & 159 & 207 & 188 & 167 & 171 & 176 & 162 & 160 & 158 & 151 & 132 & 126 & 105 & 107 & 96 & 99 & 81 & 65 \\
\hline 1.991 & 161 & 0 & 135 & 190 & 173 & 164 & 165 & 175 & 158 & 160 & 163 & 150 & 137 & 121 & 107 & 107 & 94 & 98 & 84 & 76 \\
\hline 1.992 & 214 & 156 & 0 & 156 & 166 & 177 & 179 & 185 & 170 & 178 & 180 & 161 & 149 & 134 & 114 & 120 & 108 & 106 & 100 & 91 \\
\hline 1.993 & 222 & 196 & 148 & 0 & 113 & 158 & 163 & 185 & 166 & 180 & 189 & 165 & 153 & 149 & 129 & 129 & 121 & 119 & 99 & 95 \\
\hline 1.994 & 253 & 239 & 213 & 176 & 0 & 140 & 169 & 187 & 164 & 174 & 182 & 159 & 143 & 142 & 125 & 120 & 120 & 118 & 109 & 95 \\
\hline 1.995 & 257 & 245 & 235 & 211 & 138 & 0 & 141 & 174 & 167 & 196 & 213 & 192 & 172 & 177 & 149 & 147 & 142 & 138 & 122 & 114 \\
\hline 1.996 & 270 & 260 & 253 & 221 & 181 & 161 & 0 & 118 & 144 & 183 & 188 & 192 & 171 & 167 & 144 & 147 & 141 & 135 & 118 & 113 \\
\hline 1.997 & 263 & 257 & 250 & 239 & 207 & 187 & 126 & 0 & 121 & 174 & 205 & 191 & 177 & 171 & 149 & 153 & 147 & 143 & 120 & 111 \\
\hline 1.998 & 267 & 248 & 244 & 251 & 228 & 207 & 172 & 143 & 0 & 166 & 213 & 211 & 206 & 198 & 174 & 169 & 165 & 161 & 138 & 130 \\
\hline 1.999 & 264 & 254 & 249 & 251 & 225 & 218 & 191 & 172 & 130 & 0 & 152 & 159 & 166 & 168 & 146 & 150 & 152 & 149 & 132 & 123 \\
\hline 2.000 & 247 & 236 & 239 & 237 & 215 & 218 & 189 & 175 & 162 & 124 & 0 & 200 & 254 & 296 & 272 & 270 & 285 & 276 & 258 & 244 \\
\hline 2.001 & 233 & 217 & 216 & 220 & 196 & 202 & 193 & 180 & 175 & 160 & 206 & 0 & 185 & 258 & 228 & 253 & 263 & 249 & 241 & 243 \\
\hline 2.002 & 226 & 217 & 214 & 215 & 199 & 219 & 204 & 209 & 208 & 200 & 282 & 209 & 0 & 230 & 257 & 274 & 301 & 288 & 286 & 282 \\
\hline 2.003 & 213 & 200 & 207 & 213 & 203 & 212 & 201 & 203 & 204 & 204 & 318 & 254 & 185 & 0 & 171 & 232 & 267 & 280 & 282 & 288 \\
\hline 2.004 & 205 & 187 & 181 & 193 & 192 & 193 & 191 & 189 & 190 & 202 & 303 & 254 & 231 & 191 & 0 & 196 & 257 & 277 & 284 & 295 \\
\hline 2.005 & 188 & 171 & 172 & 183 & 186 & 194 & 192 & 196 & 209 & 220 & 328 & 281 & 251 & 228 & 172 & 0 & 178 & 242 & 262 & 264 \\
\hline 2.006 & 176 & 165 & 169 & 168 & 173 & 183 & 186 & 184 & 195 & 206 & 305 & 269 & 260 & 240 & 202 & 144 & 0 & 202 & 250 & 260 \\
\hline 2.007 & 164 & 153 & 153 & 165 & 170 & 177 & 182 & 177 & 182 & 199 & 292 & 268 & 249 & 239 & 223 & 198 & 166 & 0 & 199 & 238 \\
\hline 2.008 & 142 & 137 & 145 & 148 & 146 & 159 & 159 & 160 & 163 & 176 & 268 & 244 & 230 & 226 & 210 & 194 & 188 & 164 & 0 & 180 \\
\hline 2.009 & 130 & 125 & 132 & 139 & 142 & 152 & 147 & 146 & 149 & 163 & 247 & 230 & 206 & 208 & 189 & 171 & 172 & 165 & 137 & 0 \\
\hline 2.010 & 118 & 110 & 115 & 122 & 131 & 143 & 142 & 138 & 133 & 151 & 236 & 222 & 214 & 209 & 199 & 189 & 186 & 196 & 188 & 163 \\
\hline 2.011 & 105 & 97 & 98 & 106 & 105 & 115 & 121 & 117 & 113 & 130 & 216 & 210 & 204 & 197 & 190 & 177 & 183 & 185 & 173 & 154 \\
\hline 2.012 & 93 & 83 & 87 & 98 & 94 & 105 & 108 & 104 & 92 & 115 & 191 & 184 & 178 & 178 & 172 & 165 & 161 & 183 & 166 & 162 \\
\hline 2.013 & 80 & 73 & 80 & 83 & 80 & 93 & 92 & 93 & 81 & 104 & 177 & 168 & 159 & 163 & 151 & 154 & 162 & 168 & 160 & 167 \\
\hline 2.014 & 71 & 70 & 75 & 80 & 77 & 83 & 81 & 88 & 80 & 98 & 168 & 164 & 163 & 162 & 155 & 154 & 168 & 167 & 168 & 173 \\
\hline 2.015 & 63 & 59 & 66 & 68 & 67 & 72 & 75 & 84 & 76 & 94 & 159 & 155 & 147 & 150 & 141 & 140 & 162 & 157 & 157 & 164 \\
\hline 2.016 & 57 & 52 & 52 & 61 & 58 & 62 & 66 & 73 & 67 & 81 & 134 & 132 & 137 & 133 & 129 & 120 & 141 & 133 & 132 & 134 \\
\hline
\end{tabular}

Source: SOEP.v33, own calculations. 
Table C2: Part-time wages: Subsample sizes for each grid of quantile regressions

\begin{tabular}{|c|c|c|c|c|c|c|c|c|c|c|c|c|c|c|c|c|c|c|c|c|}
\hline & 1990 & 1991 & 1992 & 1993 & 1994 & 1995 & 1996 & 1997 & 1998 & 1999 & 2000 & 2001 & 2002 & 2003 & 2004 & 2005 & 2006 & 2007 & 2008 & 2009 \\
\hline 1.984 & 263 & 313 & 302 & 289 & 287 & 295 & 288 & 268 & 267 & 271 & 247 & 230 & 210 & 212 & 192 & 166 & 148 & 134 & 120 & 97 \\
\hline 1.985 & 252 & 296 & 289 & 274 & 279 & 281 & 283 & 271 & 264 & 275 & 248 & 243 & 222 & 221 & 207 & 184 & 166 & 154 & 136 & 110 \\
\hline 1.986 & 248 & 300 & 287 & 281 & 277 & 283 & 280 & 265 & 257 & 269 & 250 & 240 & 229 & 222 & 212 & 194 & 177 & 163 & 148 & 128 \\
\hline 1.987 & 232 & 287 & 277 & 290 & 288 & 291 & 297 & 292 & 273 & 295 & 268 & 263 & 252 & 252 & 238 & 223 & 201 & 186 & 164 & 142 \\
\hline 1.988 & 198 & 262 & 254 & 270 & 277 & 284 & 286 & 283 & 271 & 293 & 274 & 275 & 270 & 262 & 249 & 236 & 217 & 200 & 177 & 156 \\
\hline 1.989 & 181 & 258 & 265 & 283 & 282 & 300 & 295 & 300 & 289 & 315 & 306 & 303 & 293 & 288 & 269 & 247 & 237 & 222 & 199 & 173 \\
\hline 1.990 & 0 & 183 & 209 & 244 & 254 & 270 & 270 & 268 & 265 & 291 & 274 & 289 & 289 & 296 & 280 & 256 & 249 & 234 & 203 & 187 \\
\hline 1.991 & 110 & 0 & 135 & 192 & 207 & 226 & 253 & 251 & 241 & 288 & 286 & 298 & 304 & 307 & 294 & 266 & 257 & 241 & 205 & 186 \\
\hline 1.992 & 140 & 141 & 0 & 152 & 199 & 225 & 249 & 259 & 254 & 302 & 298 & 306 & 316 & 333 & 307 & 288 & 273 & 261 & 230 & 209 \\
\hline 1.993 & 181 & 200 & 146 & 0 & 153 & 205 & 236 & 253 & 254 & 306 & 291 & 303 & 321 & 330 & 316 & 299 & 273 & 270 & 242 & 222 \\
\hline 1.994 & 164 & 179 & 146 & 122 & 0 & 157 & 209 & 239 & 237 & 280 & 278 & 293 & 305 & 317 & 299 & 295 & 273 & 273 & 250 & 232 \\
\hline 1.995 & 142 & 153 & 140 & 135 & 116 & 0 & 174 & 215 & 226 & 282 & 279 & 297 & 318 & 336 & 330 & 326 & 305 & 307 & 280 & 263 \\
\hline 1.996 & 143 & 163 & 150 & 139 & 140 & 138 & 0 & 149 & 172 & 236 & 246 & 272 & 294 & 322 & 324 & 314 & 299 & 299 & 268 & 260 \\
\hline 1.997 & 131 & 145 & 144 & 136 & 145 & 161 & 145 & 0 & 139 & 222 & 237 & 271 & 296 & 315 & 319 & 312 & 294 & 303 & 275 & 264 \\
\hline 1.998 & 128 & 141 & 144 & 136 & 145 & 171 & 181 & 142 & 0 & 221 & 270 & 303 & 320 & 348 & 358 & 351 & 342 & 331 & 315 & 310 \\
\hline 1.999 & 101 & 121 & 123 & 118 & 118 & 148 & 152 & 131 & 118 & 0 & 176 & 243 & 266 & 291 & 305 & 311 & 295 & 298 & 281 & 282 \\
\hline 2.000 & 98 & 123 & 130 & 120 & 120 & 149 & 145 & 143 & 156 & 161 & 0 & 335 & 403 & 464 & 473 & 486 & 464 & 485 & 481 & 442 \\
\hline 2.001 & 95 & 109 & 118 & 111 & 119 & 145 & 141 & 133 & 151 & 174 & 270 & 0 & 307 & 392 & 431 & 453 & 434 & 458 & 446 & 421 \\
\hline 2.002 & 85 & 100 & 109 & 110 & 107 & 132 & 141 & 133 & 148 & 169 & 297 & 251 & 0 & 364 & 418 & 448 & 434 & 462 & 443 & 399 \\
\hline 2.003 & 88 & 89 & 103 & 100 & 106 & 132 & 140 & 128 & 138 & 160 & 294 & 273 & 293 & 0 & 293 & 365 & 371 & 400 & 403 & 368 \\
\hline 2.004 & 69 & 74 & 81 & 80 & 83 & 107 & 118 & 116 & 120 & 137 & 289 & 285 & 327 & 272 & 0 & 273 & 314 & 373 & 386 & 343 \\
\hline 2.005 & 79 & 76 & 84 & 82 & 82 & 114 & 113 & 113 & 109 & 133 & 271 & 287 & 315 & 310 & 243 & 0 & 244 & 322 & 353 & 320 \\
\hline 2.006 & 63 & 59 & 66 & 66 & 73 & 99 & 97 & 105 & 103 & 120 & 250 & 264 & 292 & 300 & 280 & 229 & 0 & 303 & 379 & 349 \\
\hline 2.007 & 61 & 60 & 66 & 65 & 74 & 96 & 98 & 101 & 93 & 121 & 246 & 244 & 285 & 294 & 291 & 267 & 243 & 0 & 291 & 308 \\
\hline 2.008 & 51 & 50 & 50 & 53 & 69 & 73 & 69 & 80 & 81 & 99 & 224 & 224 & 271 & 270 & 266 & 255 & 271 & 240 & 0 & 229 \\
\hline 2.009 & 45 & 44 & 43 & 44 & 56 & 69 & 76 & 78 & 81 & 101 & 206 & 214 & 246 & 248 & 258 & 241 & 258 & 261 & 221 & 0 \\
\hline 2.010 & 38 & 36 & 37 & 40 & 51 & 64 & 66 & 76 & 77 & 94 & 187 & 181 & 228 & 212 & 228 & 229 & 237 & 244 & 228 & 159 \\
\hline 2.011 & 33 & 35 & 36 & 34 & 42 & 51 & 52 & 64 & 71 & 82 & 171 & 167 & 205 & 222 & 223 & 226 & 232 & 243 & 229 & 199 \\
\hline 2.012 & 28 & 28 & 27 & 30 & 36 & 44 & 47 & 54 & 63 & 72 & 150 & 160 & 196 & 200 & 193 & 196 & 206 & 226 & 221 & 191 \\
\hline 2.013 & 21 & 24 & 25 & 26 & 34 & 42 & 40 & 50 & 50 & 60 & 131 & 139 & 179 & 182 & 185 & 166 & 199 & 201 & 203 & 191 \\
\hline 2.014 & 17 & 23 & 23 & 25 & 32 & 37 & 33 & 42 & 45 & 55 & 121 & 128 & 154 & 164 & 169 & 161 & 178 & 195 & 196 & 185 \\
\hline 2.015 & 15 & 18 & 21 & 22 & 27 & 31 & 23 & 34 & 36 & 51 & 107 & 110 & 132 & 140 & 141 & 140 & 154 & 150 & 164 & 160 \\
\hline 2.016 & 9 & 12 & 15 & 16 & 21 & 28 & 22 & 33 & 35 & 43 & 99 & 98 & 126 & 130 & 131 & 130 & 148 & 147 & 149 & 150 \\
\hline
\end{tabular}

Source: SOEP.v33, own calculations. 
Table C3: Full-time wages: Subsample sizes for each grid of quantile regressions

\begin{tabular}{|c|c|c|c|c|c|c|c|c|c|c|c|c|c|c|c|c|c|c|c|c|c|c|c|c|c|c|}
\hline & 1984 & 1985 & 1986 & 1987 & 1988 & 1989 & 1990 & 1991 & 1992 & 1993 & 1994 & 1995 & 1996 & 1997 & 1998 & 1999 & 2000 & 2001 & 2002 & 2003 & 2004 & 2005 & 2006 & 2007 & 2008 & 2009 \\
\hline 1990 & 402 & 452 & 518 & 582 & 667 & 803 & 1.039 & & & & & & & & & & & & & & & & & & & \\
\hline 1991 & 363 & 398 & 448 & 501 & 585 & 699 & 797 & 1.030 & & & & & & & & & & & & & & & & & & \\
\hline 1992 & 312 & 342 & 386 & 434 & 504 & 598 & 677 & 777 & 998 & & & & & & & & & & & & & & & & & \\
\hline 1993 & 281 & 307 & 334 & 388 & 443 & 546 & 598 & 672 & 764 & 1.009 & & & & & & & & & & & & & & & & \\
\hline 1994 & 228 & 242 & 267 & 319 & 364 & 447 & 493 & 557 & 624 & 736 & 933 & & & & & & & & & & & & & & & \\
\hline 1995 & 204 & 220 & 244 & 290 & 318 & 387 & 437 & 486 & 539 & 624 & 707 & 982 & & & & & & & & & & & & & & \\
\hline 1996 & 191 & 204 & 230 & 265 & 288 & 350 & 385 & 429 & 472 & 553 & 609 & 743 & 953 & & & & & & & & & & & & & \\
\hline 1997 & 168 & 182 & 209 & 237 & 266 & 318 & 351 & 387 & 423 & 485 & 527 & 636 & 733 & 932 & & & & & & & & & & & & \\
\hline 1998 & 141 & 155 & 177 & 202 & 222 & 271 & 298 & 336 & 360 & 407 & 448 & 537 & 606 & 685 & 970 & & & & & & & & & & & \\
\hline 1999 & 126 & 135 & 151 & 179 & 196 & 240 & 260 & 292 & 319 & 355 & 408 & 478 & 532 & 600 & 753 & 987 & & & & & & & & & & \\
\hline 2000 & 128 & 129 & 143 & 171 & $\begin{array}{l}187 \\
163\end{array}$ & 211 & $\begin{array}{l}235 \\
210\end{array}$ & $\begin{array}{l}259 \\
239\end{array}$ & $\begin{array}{l}284 \\
257\end{array}$ & $\begin{array}{r}315 \\
315\end{array}$ & $\begin{array}{l}355 \\
339\end{array}$ & $\begin{array}{l}409 \\
368\end{array}$ & 464 & 506 & 617 & 736 & 1.527 & & & & & & & & & \\
\hline $\begin{array}{l}2001 \\
2002\end{array}$ & $\begin{array}{c}113 \\
97\end{array}$ & $\begin{array}{l}115 \\
101\end{array}$ & $\begin{array}{l}133 \\
113\end{array}$ & $\begin{array}{l}153 \\
133\end{array}$ & $\begin{array}{l}163 \\
139\end{array}$ & 192 & $\begin{array}{l}210 \\
178\end{array}$ & $\begin{array}{l}236 \\
194\end{array}$ & 257 & $\begin{array}{l}283 \\
245\end{array}$ & $\begin{array}{l}319 \\
269\end{array}$ & 368 & 391 & 433 & 516 & 616 & 1.181 & 1.474 & & & & & & & & \\
\hline $\begin{array}{l}2002 \\
2003\end{array}$ & 87 & 90 & 97 & 118 & $\begin{array}{l}139 \\
124\end{array}$ & $\begin{array}{l}160 \\
147\end{array}$ & $\begin{array}{l}178 \\
168\end{array}$ & $\begin{array}{l}194 \\
186\end{array}$ & $\begin{array}{l}216 \\
200\end{array}$ & $\begin{array}{l}245 \\
212\end{array}$ & $\begin{array}{l}269 \\
237\end{array}$ & $\begin{array}{l}318 \\
280\end{array}$ & $\begin{array}{l}342 \\
308\end{array}$ & 364 & $\begin{array}{l}437 \\
302\end{array}$ & 515 & 964 & 1.076 & $\begin{array}{l}1.536 \\
1.152\end{array}$ & 1511 & & & & & & \\
\hline 2004 & 77 & 84 & 89 & 106 & 113 & 131 & 151 & 162 & 182 & $\begin{array}{l}212 \\
189\end{array}$ & $\begin{array}{l}237 \\
213\end{array}$ & $\begin{array}{l}280 \\
254\end{array}$ & $\begin{array}{l}308 \\
277\end{array}$ & $\begin{array}{l}333 \\
302 \\
302\end{array}$ & $\begin{array}{l}392 \\
356\end{array}$ & $\begin{array}{l}464 \\
416\end{array}$ & $\begin{array}{l}843 \\
747\end{array}$ & $\begin{array}{l}929 \\
830\end{array}$ & $\begin{array}{l}1.182 \\
1.024\end{array}$ & $\begin{array}{l}1.515 \\
1.144\end{array}$ & 1.412 & & & & & \\
\hline 2005 & 71 & 74 & 75 & 89 & 102 & 123 & 133 & 150 & 161 & 172 & 191 & 227 & 241 & 261 & 310 & 358 & 645 & 713 & 886 & 987 & 1.067 & 1.358 & & & & \\
\hline 2006 & 60 & 66 & 64 & 76 & 88 & 106 & 115 & 126 & 136 & 149 & 164 & 198 & 217 & 231 & 274 & 320 & 582 & 641 & 783 & 867 & 931 & 1.061 & 1.404 & & & \\
\hline 2007 & 54 & 60 & 57 & 63 & 75 & 95 & 100 & 109 & 122 & 132 & 143 & 178 & 190 & 205 & 241 & 282 & 499 & 559 & 686 & 739 & 790 & 878 & 1.058 & 1.345 & & \\
\hline 2008 & 52 & 57 & 55 & 64 & 74 & 90 & 96 & 96 & 104 & 120 & 127 & 153 & 173 & 184 & 209 & 243 & 429 & 483 & 595 & 649 & 696 & 767 & 907 & 1.009 & 1.284 & \\
\hline 2009 & 48 & 54 & 51 & 64 & 67 & 89 & 96 & 91 & 94 & 106 & 115 & 133 & 151 & 163 & 185 & 216 & 373 & 410 & 514 & 561 & 598 & 666 & 782 & 853 & 953 & 1.208 \\
\hline 2010 & & & & & & & 73 & 75 & 73 & 81 & 86 & 100 & 116 & 123 & 147 & 177 & 308 & 349 & 418 & 463 & 496 & 543 & 655 & 695 & 766 & 872 \\
\hline 2011 & & & & & & & 71 & 67 & 64 & 74 & 80 & 95 & 109 & 113 & 132 & 154 & 267 & 298 & 358 & 400 & 425 & 465 & 547 & 598 & 645 & 742 \\
\hline 2012 & & & & & & & 68 & 66 & 65 & 68 & 76 & 90 & 101 & 107 & 109 & 129 & 240 & 258 & 298 & 330 & 359 & 389 & 463 & 483 & 526 & 602 \\
\hline 2013 & & & & & & & 71 & 62 & 61 & 68 & 73 & 80 & 91 & 92 & 99 & 111 & 202 & 213 & 253 & 278 & 301 & 341 & 386 & 425 & 451 & 508 \\
\hline 2014 & & & & & & & 63 & 54 & 50 & 58 & 61 & 72 & 87 & 85 & 90 & 100 & 183 & 189 & 228 & 250 & 269 & 301 & 344 & 377 & 388 & 440 \\
\hline 2015 & & & & & & & 56 & 50 & 46 & 51 & 60 & 71 & 81 & 78 & 84 & 91 & 164 & 170 & 202 & 222 & 237 & 265 & 288 & 315 & 325 & 361 \\
\hline 2016 & & & & & & & 49 & 46 & 46 & 49 & 51 & 62 & 68 & 70 & 74 & 79 & 148 & 154 & 183 & 199 & 210 & 236 & 251 & 282 & 300 & 329 \\
\hline
\end{tabular}


Table C4: Part-time wages: Subsample sizes for each grid of quantile regressions

\begin{tabular}{|c|c|c|c|c|c|c|c|c|c|c|c|c|c|c|c|c|c|c|c|c|c|c|c|c|c|c|}
\hline & 1984 & 1985 & 1986 & 1987 & 1988 & 1989 & 1990 & 1991 & 1992 & 1993 & 1994 & 1995 & 1996 & 1997 & 1998 & 1999 & 2000 & 2001 & 2002 & 2003 & 2004 & 2005 & 2006 & 2007 & 2008 & 2009 \\
\hline 1990 & 180 & 195 & 224 & 251 & 296 & 331 & 543 & & & & & & & & & & & & & & & & & & & \\
\hline $\begin{array}{l}1990 \\
1991\end{array}$ & $\begin{array}{l}180 \\
175\end{array}$ & $\begin{array}{l}195 \\
193\end{array}$ & $\begin{array}{l}224 \\
222\end{array}$ & $\begin{array}{l}201 \\
246\end{array}$ & $\begin{array}{l}290 \\
287\end{array}$ & $\begin{array}{l}391 \\
296\end{array}$ & $\begin{array}{l}543 \\
387\end{array}$ & 600 & & & & & & & & & & & & & & & & & & \\
\hline 1992 & 145 & 163 & 186 & $\begin{array}{l}240 \\
202\end{array}$ & $\begin{array}{l}201 \\
239\end{array}$ & $\begin{array}{l}290 \\
246\end{array}$ & $\begin{array}{l}301 \\
319\end{array}$ & 406 & 577 & & & & & & & & & & & & & & & & & \\
\hline 1993 & 131 & 147 & $\begin{array}{l}100 \\
166\end{array}$ & 172 & 205 & 205 & 257 & $\begin{array}{l}400 \\
323\end{array}$ & 379 & 565 & & & & & & & & & & & & & & & & \\
\hline 1994 & 116 & 133 & 163 & 164 & 190 & 202 & 245 & 300 & 331 & 379 & 575 & & & & & & & & & & & & & & & \\
\hline 1995 & 104 & 126 & 146 & 151 & 180 & 185 & 238 & 295 & 311 & 337 & 403 & 645 & & & & & & & & & & & & & & \\
\hline 1996 & 89 & 107 & $\begin{array}{l}126 \\
126\end{array}$ & $\begin{array}{l}129 \\
129\end{array}$ & 158 & 166 & 213 & 252 & 273 & 294 & 335 & 441 & 655 & & & & & & & & & & & & & \\
\hline 1997 & 82 & 95 & 115 & 118 & 142 & 141 & 199 & 236 & 240 & 262 & 293 & 380 & 451 & 634 & & & & & & & & & & & & \\
\hline 1998 & 64 & 86 & 105 & 113 & 133 & 126 & 168 & 211 & 213 & 233 & 257 & 324 & 379 & 426 & 677 & & & & & & & & & & & \\
\hline 1999 & 55 & 71 & 90 & 94 & 114 & 112 & 160 & 186 & 197 & 213 & 254 & 305 & 360 & 389 & 492 & 749 & & & & & & & & & & \\
\hline 2000 & 42 & 63 & 78 & 86 & 96 & 93 & 134 & 148 & 155 & 176 & 210 & 260 & 306 & 329 & 390 & 499 & 1.352 & & & & & & & & & \\
\hline 2001 & 49 & 59 & 80 & 79 & 87 & 86 & 120 & 135 & 146 & 166 & 193 & 230 & 273 & 288 & 346 & 428 & 989 & 1.387 & & & & & & & & \\
\hline 2002 & 43 & 54 & 72 & 75 & 75 & 79 & 111 & 122 & 125 & 140 & 172 & 207 & 240 & 258 & 317 & 386 & 855 & 955 & 1.512 & & & & & & & \\
\hline 2003 & 33 & 44 & 66 & 63 & 71 & 70 & 95 & 113 & 113 & 128 & 151 & 182 & 209 & 236 & 284 & 353 & 754 & 843 & 1.060 & 1.508 & & & & & & \\
\hline 2004 & 29 & 36 & 54 & 55 & 63 & 70 & 91 & 105 & 112 & 123 & 156 & 183 & 199 & 224 & 275 & 338 & 676 & 742 & 922 & 1.076 & 1.451 & & & & & \\
\hline 2005 & 26 & 31 & 43 & 46 & 53 & 60 & 78 & 90 & 95 & 101 & 135 & 151 & 177 & 204 & 250 & 303 & 613 & 658 & 827 & 932 & 1.058 & 1.393 & & & & \\
\hline 2006 & 22 & 23 & 34 & 37 & 43 & 47 & 65 & 77 & 81 & 95 & 117 & 140 & 160 & 187 & 222 & 284 & 557 & 598 & 734 & 822 & 910 & 990 & 1.429 & & & \\
\hline 2007 & 15 & 16 & 27 & 26 & 28 & 31 & 51 & 60 & 63 & 74 & 91 & 108 & 132 & 154 & 192 & 241 & 481 & 526 & 640 & 736 & 781 & 848 & 1.027 & 1.401 & & \\
\hline 2008 & 14 & 12 & 22 & 24 & $\begin{array}{l}29 \\
22\end{array}$ & 25 & 47 & 55 & 61 & 66 & 79 & 101 & 124 & 142 & 173 & 222 & 410 & 447 & 547 & 631 & 669 & 717 & 838 & 958 & 1.308 & \\
\hline 2009 & 14 & 12 & 16 & 17 & 23 & 21 & 37 & 48 & 53 & 59 & 67 & 78 & 93 & 110 & 138 & 179 & 338 & 364 & 480 & 545 & 587 & 630 & 728 & 799 & 896 & 1.188 \\
\hline 2010 & & & & & & & $\begin{array}{l}31 \\
30\end{array}$ & $\begin{array}{l}37 \\
36\end{array}$ & $\begin{array}{l}41 \\
38\end{array}$ & 44 & 52 & 66 & $\begin{array}{l}75 \\
79\end{array}$ & 93 & 117 & 148 & 298 & 324 & 406 & 478 & 489 & 528 & 611 & 686 & 753 & 837 \\
\hline 2011 & & & & & & & 30 & 36 & 38 & 43 & 50 & 68 & 79 & 93 & 110 & 135 & 260 & 274 & 341 & 390 & 413 & 441 & 526 & 592 & 653 & 701 \\
\hline $\begin{array}{l}2012 \\
2013\end{array}$ & & & & & & & $\begin{array}{l}21 \\
18\end{array}$ & $\begin{array}{l}29 \\
27\end{array}$ & $\begin{array}{l}32 \\
30\end{array}$ & $\begin{array}{l}32 \\
30\end{array}$ & $\begin{array}{l}38 \\
38\end{array}$ & $\begin{array}{l}52 \\
46\end{array}$ & 62 & $\begin{array}{l}75 \\
68\end{array}$ & $\begin{array}{l}79 \\
77\end{array}$ & $\begin{array}{l}99 \\
95\end{array}$ & $\begin{array}{l}199 \\
179\end{array}$ & $\begin{array}{l}204 \\
188\end{array}$ & $\begin{array}{l}251 \\
233\end{array}$ & $\begin{array}{l}310 \\
278\end{array}$ & 325 & 358 & $\begin{array}{l}425 \\
272\end{array}$ & 464 & 495 & 541 \\
\hline $\begin{array}{l}2013 \\
2014\end{array}$ & & & & & & & $\begin{array}{l}18 \\
18\end{array}$ & $\begin{array}{l}27 \\
25\end{array}$ & $\begin{array}{l}30 \\
30\end{array}$ & $\begin{array}{l}30 \\
26\end{array}$ & $\begin{array}{l}38 \\
32\end{array}$ & $\begin{array}{l}46 \\
39\end{array}$ & $\begin{array}{l}60 \\
51\end{array}$ & $\begin{array}{l}68 \\
63\end{array}$ & $\begin{array}{l}77 \\
61\end{array}$ & $\begin{array}{l}95 \\
81\end{array}$ & $\begin{array}{l}179 \\
159\end{array}$ & $\begin{array}{l}188 \\
164\end{array}$ & $\begin{array}{l}233 \\
204\end{array}$ & $\begin{array}{l}278 \\
249\end{array}$ & $\begin{array}{l}285 \\
244\end{array}$ & $\begin{array}{l}318 \\
278\end{array}$ & $\begin{array}{l}372 \\
327\end{array}$ & $\begin{array}{l}420 \\
358\end{array}$ & $\begin{array}{l}449 \\
307\end{array}$ & 477 \\
\hline $\begin{array}{l}2014 \\
2015\end{array}$ & & & & & & & $\begin{array}{l}18 \\
13\end{array}$ & $\begin{array}{l}25 \\
22\end{array}$ & $\begin{array}{l}30 \\
21\end{array}$ & $\begin{array}{l}26 \\
21\end{array}$ & $\begin{array}{l}32 \\
28\end{array}$ & $\begin{array}{l}39 \\
32\end{array}$ & $\begin{array}{l}51 \\
42\end{array}$ & $\begin{array}{l}63 \\
48\end{array}$ & $\begin{array}{l}61 \\
52\end{array}$ & $\begin{array}{l}81 \\
71\end{array}$ & $\begin{array}{l}159 \\
133\end{array}$ & $\begin{array}{l}164 \\
13\end{array}$ & $\begin{array}{l}204 \\
166\end{array}$ & $\begin{array}{l}249 \\
199\end{array}$ & $\begin{array}{l}244 \\
210\end{array}$ & $\begin{array}{l}270 \\
225\end{array}$ & $\begin{array}{l}327 \\
276\end{array}$ & $\begin{array}{l}358 \\
322\end{array}$ & $\begin{array}{l}387 \\
335\end{array}$ & $\begin{array}{l}412 \\
365\end{array}$ \\
\hline 2016 & & & & & & & 10 & 17 & 18 & 21 & 25 & 26 & 38 & 41 & 43 & 60 & 108 & 112 & 128 & 159 & 173 & 187 & 214 & 258 & 272 & 297 \\
\hline
\end{tabular}




\section{Appendix: Robustness Checks}

In this section, I present results of several robustness checks that largely confirm the stability of the main results of the paper. First, I replicate the results on the corrected part-time wage gap with alternative thresholds on weekly hours determining full- and part-time employment (section D.1). Next, I discuss possible alternative weighting rules of multiple imputations (section D.3) and, finally, I reflect on the sensitivity of the results to the alternative imputation rule used for recovering wages of those who I never observed engaging in full- or part-time work (section D.4). The existence of a corrected part-time wage penalty at the lowest wage quartile is robust to all dimensions explored in this section.

\section{D.1. Sensitivity of the results to the chosen hours cut-off}

Tables D1 and D2 display figures on the observed and corrected part-time wage gap using two alternative hours thresholds (30 and 35 working hours per week, respectively). Both the observed and the corrected part-time wage gap stay qualitatively the same if the hours threshold is changed to 30 or 35 working hours per week.

Table D1: Part-Time Gap, threshold at 30 hours per week

\begin{tabular}{|c|c|c|c|c|}
\hline & 1990-1994 & 1995-1999 & 2000-2004 & 2005-2009 \\
\hline \multicolumn{5}{|c|}{ evaluated at the 10 th percentile } \\
\hline$G_{o b s}(\tau=.10)$ & $0.25^{*}$ & $0.28^{*}$ & $0.36^{*}$ & $0.35^{*}$ \\
\hline$\widehat{G}_{\text {corr }}(\tau=.10)$ & $0.10^{*}$ & $0.22^{*}$ & $0.13^{*}$ & $0.08^{*}$ \\
\hline \multicolumn{5}{|c|}{ evaluated at the 25 th percentile } \\
\hline$G_{o b s}(\tau=.25)$ & $0.18^{*}$ & $0.20^{*}$ & $0.25^{*}$ & $0.28^{*}$ \\
\hline$\widehat{G}_{\text {corr }}(\tau=.25)$ & $0.05^{*}$ & $0.13^{*}$ & $0.04^{*}$ & $0.03^{*}$ \\
\hline \multicolumn{5}{|c|}{ evaluated at the 50 th percentile } \\
\hline$G_{o b s}(\tau=.50)$ & $0.10^{*}$ & $0.10^{*}$ & $0.17^{*}$ & $0.20^{*}$ \\
\hline$\widehat{G}_{\text {corr }}(\tau=.50)$ & 0.00 & $0.06^{*}$ & $-0.03^{*}$ & 0.01 \\
\hline \multicolumn{5}{|c|}{ evaluated at the 75 th percentile } \\
\hline$G_{o b s}(\tau=.75)$ & 0.01 & 0.03 & $0.11^{*}$ & $0.15^{*}$ \\
\hline$\widehat{G}_{\text {corr }}(\tau=.75)$ & $-0.04^{*}$ & -0.01 & $-0.07^{*}$ & -0.01 \\
\hline \multicolumn{5}{|c|}{ evaluated at the 90th percentile } \\
\hline$G_{o b s}(\tau=.90)$ & $-0.13^{*}$ & $-0.15^{*}$ & 0.03 & $0.12^{*}$ \\
\hline$\widehat{G}_{\text {corr }}(\tau=.90)$ & $-0.14^{*}$ & $-0.10^{*}$ & $-0.10^{*}$ & $-0.04^{*}$ \\
\hline
\end{tabular}

\section{D.2. Results using contractual- instead of actual- working hours}

Table D3 presents figures on the observed and corrected part-time wage gap using contractual working hours plus paid overtime instead of actual working hours. The concern here is that (paid) overtime hours may be systematically different for full- and part-time employment, thereby 
Table D2: Part-Time Gap, threshold at 35 hours per week

\begin{tabular}{|c|c|c|c|c|}
\hline & 1990-1994 & 1995-1999 & 2000-2004 & 2005-2009 \\
\hline \multicolumn{5}{|c|}{ evaluated at the 10th percentile } \\
\hline$G_{o b s}(\tau=.10)$ & $0.23^{*}$ & $0.26^{*}$ & $0.33^{*}$ & $0.33^{*}$ \\
\hline$\widehat{G}_{\text {corr }}(\tau=.10)$ & $0.12^{*}$ & $0.22^{*}$ & $0.12^{*}$ & $0.13^{*}$ \\
\hline \multicolumn{5}{|c|}{ evaluated at the 25th percentile } \\
\hline$G_{o b s}(\tau=.25)$ & $0.18^{*}$ & $0.17^{*}$ & $0.22^{*}$ & $0.26^{*}$ \\
\hline$\widehat{G}_{\text {corr }}(\tau=.25)$ & $0.07^{*}$ & $0.13^{*}$ & 0.01 & $0.04^{*}$ \\
\hline \multicolumn{5}{|c|}{ evaluated at the 50th percentile } \\
\hline$G_{o b s}(\tau=.50)$ & $0.10^{*}$ & $0.07^{*}$ & $0.13^{*}$ & $0.18^{*}$ \\
\hline$\widehat{G}_{\text {corr }}(\tau=.50)$ & 0.01 & $0.03^{*}$ & $-0.06^{*}$ & -0.01 \\
\hline \multicolumn{5}{|c|}{ evaluated at the 75th percentile } \\
\hline$G_{o b s}(\tau=.75)$ & 0.01 & 0.01 & $0.08^{*}$ & $0.13^{*}$ \\
\hline$\widehat{G}_{\text {corr }}(\tau=.75)$ & $-0.05^{*}$ & $-0.05^{*}$ & $-0.09^{*}$ & $-0.04^{*}$ \\
\hline \multicolumn{5}{|c|}{ evaluated at the 90th percentile } \\
\hline$G_{o b s}(\tau=.90)$ & $-0.12^{*}$ & $-0.13^{*}$ & 0.02 & $0.11^{*}$ \\
\hline$\widehat{G}_{\text {corr }}(\tau=.90)$ & $-0.13^{*}$ & $-0.10^{*}$ & $-0.09^{*}$ & $-0.05^{*}$ \\
\hline \multicolumn{5}{|c|}{ Comments: Units are log-point differences between inverse cumulative distributions. } \\
\hline \multicolumn{5}{|c|}{ Unweighted average of multiple imputations. ${ }^{*}$ Statistical significance at the } \\
\hline \multicolumn{5}{|c|}{$5 \%$ level (computed by bootstrap with 200 replications). } \\
\hline
\end{tabular}

biasing my results in one or the other direction. However, Table D3 shows that the results remain qualitatively the same regardless of the definition of working hours.

\section{D.3. Weighting of multiple imputations}

Multiple imputations are available for individuals whom I observe working full-time (part-time) for several years. This is the case for $34 \%$ to $46 \%$ of all person-year observations who require imputations in each survey year. ${ }^{21}$

If individuals would hold the same conditional rank all years they work in a particular type of employment, then multiple imputations available for an individual would be identical and there would be no need to deal with this issue. However, in the data one observes that individuals hold different conditional ranks over the years. While this does not contravene the (conditional) rank similarity assumption, ${ }^{22}$ it poses the question of how to best use the several available imputations for some individuals.

Whereas the persistence of wage shocks suffered by individuals is outside of the scope of this paper, I replicate the main results with two alternative weighting schemes in order to determine to what extent my results are driven by the choice of weights.

First, I use a closest-neighbor approach, in which the imputation that relies on information chronologically closer to the year of interest gets a weight of one and the remaining available

\footnotetext{
${ }^{21}$ See Table A3 in the Appendix for the exact figures.

${ }^{22}$ See Chernozhukov and Hansen (2005) for a discussion on why unsystematic slippages on individuals' conditional ranks do not pose a problem.
} 
Table D3: Part-time gap, contractual working hours

1990-1994 1995-1999 2000-2004 2005-2009

\begin{tabular}{|c|c|c|c|c|}
\hline $\begin{array}{l}\text { evaluated at the } \\
G_{\text {obs }}(\tau=.10)\end{array}$ & $\begin{array}{c}\text { th } \text { perce } \\
0.21\end{array}$ & 0.25 & 0.36 & 0.35 \\
\hline$\widehat{G}_{\text {corr }}(\tau=.10)$ & $0.15^{*}$ & $0.23^{*}$ & $0.21^{*}$ & $0.19^{*}$ \\
\hline \multicolumn{5}{|c|}{ evaluated at the $25^{\text {th }}$ percentile } \\
\hline$G_{o b s}(\tau=.25)$ & 0.16 & 0.17 & 0.25 & 0.26 \\
\hline$\widehat{G}_{\text {corr }}(\tau=.25)$ & $0.07^{*}$ & $0.14^{*}$ & $0.09 *$ & $0.11^{*}$ \\
\hline \multicolumn{5}{|c|}{ evaluated at the $50^{\text {th }}$ percentile } \\
\hline$G_{o b s}(\tau=.50)$ & 0.07 & 0.07 & 0.15 & 0.18 \\
\hline$\widehat{G}_{\text {corr }}(\tau=.50)$ & 0.00 & $0.05^{*}$ & $-0.02^{*}$ & 0.01 \\
\hline \multicolumn{5}{|c|}{ evaluated at the $75^{\text {th }}$ percentile } \\
\hline$G_{o b s}(\tau=.75)$ & -0.03 & -0.01 & 0.09 & 0.14 \\
\hline$\widehat{G}_{\text {corr }}(\tau=.75)$ & $-0.03^{*}$ & 0.00 & $-0.06^{*}$ & 0.00 \\
\hline \multicolumn{5}{|c|}{ evaluated at the $90^{\text {th }}$ percentile } \\
\hline$G_{o b s}(\tau=.90)$ & -0.26 & -0.25 & 0.01 & 0.07 \\
\hline$\widehat{G}_{\text {corr }}(\tau=.90)$ & $-0.14^{*}$ & $-0.10^{*}$ & $-0.05^{*}$ & 0.02 \\
\hline
\end{tabular}

Comments: Units are log-point differences between inverse cumulative distributions. Unweighted average of multiple imputations.

Source: SOEP.v33,own calculations.

imputations are not used at all. Formally:

$$
d_{i k n}^{B}= \begin{cases}1 & \text { if }\left|y_{n}-y_{k}\right|<\left|y_{j}-y_{k}\right| \forall n \neq j \\ 1 & \text { if }\left|y_{n}-y_{k}\right|=\left|y_{j}-y_{k}\right| \text { and } y_{n}>y_{j} \forall n \neq j \\ 0 & \text { if }\left|y_{n}-y_{k}\right|=\left|y_{j}-y_{k}\right| \text { and } y_{n}<y_{j} \forall n \neq j \\ 0 & \text { if }\left|y_{n}-y_{k}\right|>\left|y_{j}-y_{k}\right| \forall n \neq j\end{cases}
$$

Secondly, I replicate the main results with an average of all available imputations which gives a higher weight to imputations relying in information chronologically closer to the year of interest than imputations relying in more distant information. Under this scheme, contrary to the closest neighbour approach, all imputations are used. The weighting function in this case reads:

$$
d_{i k n}^{C}=\frac{\sum_{n=1}^{N}\left(y_{n}-y_{k}\right)^{2}}{\left(y_{n}-y_{k}\right)^{2}} \cdot\left[\sum_{n=1}^{N} \frac{\sum_{n=1}^{N}\left(y_{n}-y_{k}\right)^{2}}{\left(y_{n}-y_{k}\right)^{2}}\right]^{-1}
$$

Table D4 shows that the results are robust to the choice of weighting rule, as there are no qualitative differences among the two. This, in turn, suggests that multiple imputations available for each individual are rather stable.

\section{D.4. Sensitivity analysis of the median imputation}

This section deals with the sensitivity of the results to the median imputation of wages for those individuals who I never observe working in any of the two work arrangements under study. Given that this affects a substantial share of observations every year, it is important to check to what 
Table D4: Sensitivity to the weighting scheme of multiple imputations

1990-1994 1995-1999 2000-2004 2005-2009

\begin{tabular}{lcccc}
\hline \multicolumn{6}{l}{ (A) Closest neighbor imputation } \\
\hline$\widehat{G}_{\text {corr }}(\tau=.10)$ & $0.09^{*}$ & $0.25^{*}$ & $0.15^{*}$ & $0.12^{*}$ \\
$\widehat{G}_{\text {corr }}(\tau=.25)$ & $0.04^{*}$ & $0.16^{*}$ & $0.04^{*}$ & $0.06^{*}$ \\
$\widehat{G}_{\text {corr }}(\tau=.50)$ & 0.00 & $0.06^{*}$ & $-0,04^{*}$ & -0.01 \\
$\widehat{G}_{\text {corr }}(\tau=.75)$ & $-0.05^{*}$ & $-0.04^{*}$ & $-0,07^{*}$ & $-0.04^{*}$ \\
$\widehat{G}_{\text {corr }}(\tau=.90)$ & $-0.18^{*}$ & $-0.15^{*}$ & $-0.09^{*}$ & $-0.07^{*}$ \\
\hline
\end{tabular}

(B) Weighted average of multiple imputations

\begin{tabular}{lcccc}
\hline$\widehat{G}_{\text {corr }}(\tau=.10)$ & $0.10^{*}$ & $0.22^{*}$ & $0.13^{*}$ & $0.11^{*}$ \\
$\widehat{G}_{\text {corr }}(\tau=.25)$ & $0.05^{*}$ & $0.14^{*}$ & $0.03^{*}$ & $0.04^{*}$ \\
$\widehat{G}_{\text {corr }}(\tau=.50)$ & 0.00 & $0.06^{*}$ & $-0.05^{*}$ & -0.01 \\
$\widehat{G}_{\text {corr }}(\tau=.75)$ & $-0.06^{*}$ & -0.02 & $-0.08^{*}$ & $-0.03^{*}$ \\
$\widehat{G}_{\text {corr }}(\tau=.90)$ & $-0.15^{*}$ & $-0.11^{*}$ & $-0.09^{*}$ & $-0.06^{*}$ \\
\hline
\end{tabular}

Comments: Units are log-point differences between inverse cumulative distributions.

*Statistical significance at the 5\% level (computed by bootstrap with 200 replications).

Source: SOEP.v33,own calculations.

extent the results are driven by the additional assumption made on the unobservable characteristics of this group.

Table D5 shows results on the corrected part-time wage gap if a random conditional rank is allocated to individuals for whom I do not observe either a full- or a part-time wage. Results up to the $75^{\text {th }}$ percentile are qualitatively equivalent to the main results. However, corrected premia at the very top of the distribution become larger under the random conditional rank allocation. This makes sense as wage dispersion rises with skill, so that the effect of different conditional ranks is more noticeable at the top of the distribution.

Table D5: Robustness Check: Random Alternative Imputation

\begin{tabular}{lcccc}
\hline & $\mathbf{1 9 9 0 - 1 9 9 4}$ & $\mathbf{1 9 9 5 - 1 9 9 9}$ & $\mathbf{2 0 0 0 - 2 0 0 4}$ & $\mathbf{2 0 0 5 - 2 0 0 9}$ \\
\hline$\widehat{G}_{\text {corr }}(\tau=.10)$ & $0.13^{*}$ & $0.28^{*}$ & $0.12^{*}$ & $0.12^{*}$ \\
$\widehat{G}_{\text {corr }}(\tau=.25)$ & $0.09^{*}$ & $0.18^{*}$ & $0.07^{*}$ & $0.09^{*}$ \\
$\widehat{G}_{\text {corr }}(\tau=.50)$ & $0.02^{*}$ & $0.06^{*}$ & -0.02 & $0.03^{*}$ \\
$\widehat{G}_{\text {corr }}(\tau=.75)$ & $-0.07^{*}$ & $-0.04^{*}$ & $-0.09^{*}$ & -0.01 \\
$\widehat{G}_{\text {corr }}(\tau=.90)$ & $-0.22^{*}$ & $-0.15^{*}$ & $-0.14^{*}$ & $-0.07^{*}$ \\
\hline Comments: Units are log-point differences between the relevant inverse cumulative distributions. \\
Unweighted average of multiple imputations. ${ }^{*}$ Statistical significance at the $5 \%$ level \\
(computed by bootstrap with 200 replications). \\
Source: SOEP.v33,own calculations.
\end{tabular}

An alternative suggested in the literature is to use information from individuals who I only observe working full- or part-time one year in the data. The average conditional rank of these individuals is very close to the median both for full- and part-time employment. 